Portland State University

PDXScholar

6-13-1996

\title{
Adolescents and Sex on the Soaps: A Content Analysis
}

Jenelle Gay Winter

Portland State University

Follow this and additional works at: https://pdxscholar.library.pdx.edu/open_access_etds

Part of the Speech and Rhetorical Studies Commons

Let us know how access to this document benefits you.

\section{Recommended Citation}

Winter, Jenelle Gay, "Adolescents and Sex on the Soaps: A Content Analysis" (1996). Dissertations and Theses. Paper 5211.

https://doi.org/10.15760/etd.7087

This Thesis is brought to you for free and open access. It has been accepted for inclusion in Dissertations and Theses by an authorized administrator of PDXScholar. Please contact us if we can make this document more accessible: pdxscholar@pdx.edu. 


\section{THESIS APPROVAL}

The abstract and thesis of Jenelle Gay Winter for the Master of Science in Speech

Communication were presented June 13,1996, and accepted by the thesis committee and the department.

COMMITTEE APPROVALS:

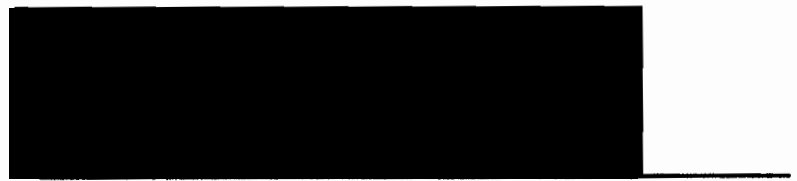

L. David Ritchie, Chair

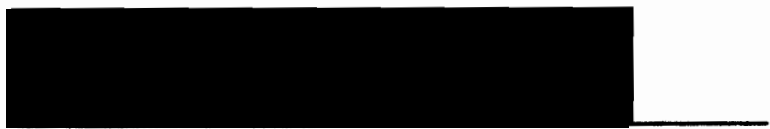

Peter Ehrenhaus

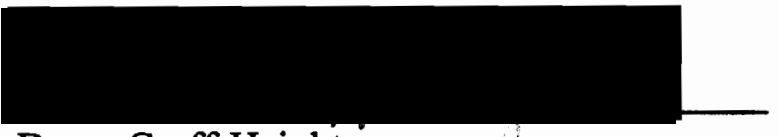

Dawn Graff-Haight

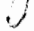

Representative of the Office of Graduate Studies

DEPARTMENT APPROVAL:

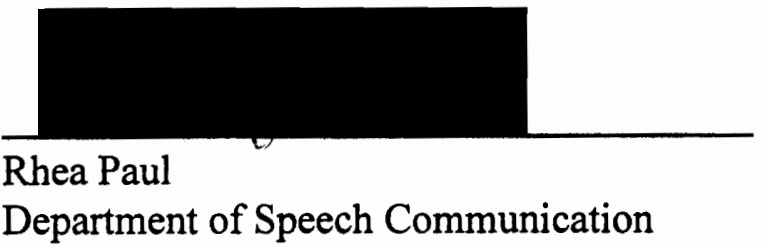

\section{ACCEPTED FOR PORTLAND STATE UNIVERSITY BY THE LIBRARY}

by

on

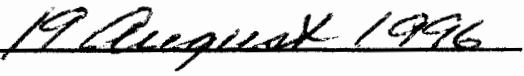




\begin{abstract}
An abstract of the thesis of Jenelle Gay Winter for the Master of Science in Speech Communication presented June 13, 1996.
\end{abstract}

Title: Adolescents and Sex on the Soaps: A Content Analysis.

This study updates prior examinations of sexual content on daytime soap operas by investigating verbal references, implied sexual acts and mentions of sexually transmitted diseases. In addition, it extends earlier work by analyzing the commitment level and age of those involved in the sexual content. Finally, this study will attempt to obtain a clear picture of what adolescents perceive while viewing these shows. This was investigated by conducting adolescent and adult focus groups to see how they talk about soap operas. Also, comparisons were made of adult and adolescent coding of the sexual content on soap operas.

All daytime soap operas were recorded twice per month for a six month period in 1995. From this sample, 36 hours of programming were coded for sexual content. For the adolescent and adult comparison studies, six adolescents and six adults from the Portland metropolitan area were selected to take part in focus groups and soap opera coding. Each of these subjects is a current soap opera viewer and all watched Days of Our Lives.

The findings in this study do not support a social learning theory account, according to which the content of television programming provides a basis for 
undesirable effects. This study shows that soap operas provide both positive and negative depictions of sexual activity. It suggests that the age and/or background of the viewer has a more significant influence on what the viewer gets from the viewing experience. 
ADOLESCENTS AND SEX ON THE SOAPS:

A CONTENT ANALYSIS

by

JENELLE GAY WINTER

A thesis submitted in partial fulfillment of the requirements for the degree of

\author{
MASTER OF SCIENCE \\ in \\ SPEECH COMMUNICATION
}

Portland State University

1996 


\section{ACKNOWLEDGMENTS}

I would like to give thanks to all of those who helped in the successful completion of this thesis. First, I would like to thank all the members of my thesis committee, Dr. David Ritchie, Dr. Peter Ehrenhaus and Dr. Dawn Graff-Haight for their time and patience. I would also like to thank them for the input and suggestions. I would especially like to thank Dr. Ritchie for the time spent in meetings and answering e-mail messages and for his encouragement when the end seemed no where in sight.

Secondly, thank you to all my fellow students. They were generous with time, suggestions and encouragement. I would like to give special thanks to those who helped me to find subjects and who answered my late-night phone calls.

My family and friends were also instrumental in the success of this project. I would like to thank them for their patience and understanding. To my friends at work, thank you for understanding my priorities. Finally, to the most patient of all, Lonnie Winter and John Clinton, thank you for loving me even when I wasn't very lovable. 


\section{Page}

Acknowledgments

List of Tables $\quad$ V

\section{CHAPTER}

I. Introduction 1

Soap Opera History 1

Sexual Television $\quad 2$

II. Literature Review 4

Sex on the Soaps 4

Research Question \#1 6

Learning Theory 6

Cultivation Effect $\quad 7$

Adolescent Television Viewing Behavior 9

Influence of Sexual Television Programming on

Adolescents 9

Research Question \#2 12

Viewer Involvement $\quad 12$

$\begin{array}{ll}\text { III. Method } & 15\end{array}$

Sample $\quad 15$

Researcher Coding $\quad 16$

Commitment Level 17

Pregnancy Prevention/STD Prevention \& Contraction $\quad 18$

Adolescent Behavior $\quad 18$

Pilot Tests 19

Subjects $\quad 20$

Focus Group and Subject Coding Procedures 21

Analysis $\quad 23$

$\begin{array}{ll}\text { IV. Results } & 25\end{array}$

Research Question \#1 25

Research Question \#2 31

Focus Group Analysis $\quad 34$ 
V. Perceptions of Soap Opera Viewing 35

Modeling Theory 35

Perceived Usefulness of Soap Operas $\quad 38$

Interactions With Characters $\quad 40$

Reasons for Viewing 41

Similarities of Adolescent and Adult Experiences 43

Perceptions of Sex on the Soaps $\quad 45$

VI. Discussion 49

Erotic Touching 49

Commitment Level $\quad 50$

Aggressive Acts $\quad 52$

Heterosexual Intercourse $\quad 53$

"Safer Sex" 56

What Do Adolescents Hear? 61

Study Limitations 64

Recommendations for Future Study 64

Summary of Findings $\quad 65$

$\begin{array}{ll}\text { References } & 67\end{array}$

Appendices

A Tools for Data Collection $\quad 72$

B Adolescent Focus Group Transcripts $\quad 77$

C Adult Focus Group Transcripts 102 


\section{LIST OF TABLES}

Table

1. Rate of sexual references in 1979, 1987, and 1995

2. Frequency of sexual references in 1979 and 1987

3. Frequency of sexual references in 1995

4. Total count of sexual references for each soap opera 31

5. Viewer perceptions of verbal references to sexual intercourse 33 


\section{Chapter I}

\section{Introduction}

The daytime soap opera was an instant success from its early days on radio. The radio drama originally played in the evenings on network radio stations. Program creators and network officials did not feel that the daytime audience was large enough to justify programming during the day (Biracree, 1994). For this reason the task of daytime production was left to local stations. In the early thirties, a schoolteacher from Ohio, named Irna Phillips, produced the first daytime drama on one of these local stations. Painted Dreams was only fifteen minutes long.

These short programs quickly grew in popularity. They helped the women who stayed home relieve the stress brought on by the depression. Through time, women have used soap operas as an escape from many of life's problems.

It was not long before sponsors of other types of programming began to realize the possible benefits of becoming involved in these new programs. According to Biracree (1994), "Soap companies plunged into the business of producing serials that featured their products, and they so dominated daytime that the serials became known as 'soap operas'." At one point, Procter and Gamble produced six soaps (Cantor \& Pingree, 1983).

In the 40 's, with the rise in popularity of television, came experiments with televised soap operas. The first soap opera on television was "A Woman to Remember" (Biracree, 1994, Cantor \& Pingree, 1983). Soon, there were as many 
televised soap operas, lifting the spirits of housewives of the 50's, as there were radio soaps for the housewives of the 30's.

Originally there was a concern that televised daytime drama would not be successful. Many network producers felt that women would be too occupied with household responsibilities (Cantor \& Pingree, 1983). This was also an early concern with television makers. They felt that the television would not be used because people had to both listen and watch. However, these concerns proved unfounded. Many people watch and listen to television, including soap operas, while performing other tasks.

Since the rise of the televised daytime soap opera, the popularity of these programs has increased beyond what the originators had imagined possible. However, along with this popularity comes the voice of the critic who is concerned with the content of these potentially influential programs. The primary concern for content of daytime soap operas seems to be that the characters are often sexually over zealous and are not particularly responsible about their sexual behavior.

\section{Sexual Television}

Network television has seen an increase in the portrayal of sexual behavior. Increased sexual content on network television can be attributed in part to the need to draw viewers back from cable television. "NYPD Blue" is an example of highly sexual network programming. This program received notoriety even before it aired. The sexual content of this program was the subject of many conversations at the time. 
Bare breasts and buttocks were shown in the premiere. Implied sexual acts are also on the rise. Greenberg et al (1986) found that unmarried intercourse occurs five times as often as married intercourse on the prime-time series adolescents watch most often.

Human sexuality is a highly charged subject. Sex on television has been difficult to regulate at a legislative level. This is primarily due to the fact that "obscenity, one type of speech not protected by the First Amendment, has not been taken by the courts to refer to sexual material" (Liebert \& Sprafkin, 1988).

The fact that adolescent girls are watching this highly sexual programming has brought forward a concern about what these girls may be learning from viewing soap operas. They are less experienced in matters of romance and love but are developing a strong interest. However, before these concerns can be justified, it is essential to first (1) obtain a clear picture of the actual sexual content of soap operas and (2) discover how adolescent viewers perceive that content. The purpose of this thesis can be broadly stated as an investigation of the sexual content of soap operas and how it is perceived by adolescent females. 


\section{Chapter II}

\section{Literature Review}

Sex on the Soaps

Other researchers have seen the importance of calculating the amount of sex portrayed on soap operas. Previous studies (Franzblau, Sprafkin \& Rubinstein, 1977; Lowry, Love \& Kirby, 1981; Lowry \& Towles, 1989; Larson, 1991; Olson, 1994) have investigated the portrayal of sex on soap operas through content analysis. The Lowry \& Towles (1989) study was used as a comparison to observe a speculated increase in the portrayal of sexual content of soap operas since the Lowry, Love \& Kirby (1981)study. Lowry \& Towles (1989) did find that the frequency of sexual content increased. They found an increase from 6.6 (1979) acts per hour to 7.4 (1987) acts per hour.

Lowry \& Towles (1989) also studied the extent to which "safer sex" was portrayed. This included mentions of pregnancy and sexually transmitted disease (STD) prevention. They found no mention of either in their study.

In a recent comparative content analysis of health issues as portrayed on soap operas, Olson (1994) tested to find if increased public concern had spread into the content of this genre. She found that mentions of pregnancy prevention increased from zero (Lowry \& Towles, 1989) to four in her sample. However, in one case the woman looking for birth control had a split personality. Her responsible half wanted to protect herself from her promiscuous half. STDs were not mentioned in a sexual 
context. There was one mention of AIDS. It was a reference to a character who had already died of the disease.

In a study on the sexual content of All My Children, Larson (1991) felt that it was important to understand the relationship of the participants involved in the sexual activity that is portrayed on daytime soap operas. According to Larson, the lack of credit given to the commitment level of unmarried partners contributes to the criticism about the morality of soap operas. Studies that analyze the sexual content of soap operas find that most sex happens between unmarried couples (Lowry, Love \& Kirby, 1981; Lowry \& Towles, 1989; Greenberg, Abelman \& Neuendorf, 1981). According to Larson, simply saying that most sex happens between unmarried couples "minimizes the prevalence of relationship commitment and exclusiveness." In her content analysis of sexual partners and their relationships, she found that only $31 \%$ of participants were married. Although this seems to suggest that most sex on the soaps is "immoral," if you take into consideration the commitment level of those who are unmarried $83 \%$ of the people who were having sex were at least committed if not married.

Except for Larson, other content analysis studies of the portrayal of sex on soap operas have characterized the participants as either married or unmarried. This may not give an accurate picture of the type of sexual activity that is portrayed on the daytime drama. This presents a need for a distinction between committed and uncommitted relationships when analyzing the sexual content of soap operas. 
Lowry, Love \& Kirby (1981) briefly mention a concern for the influence that sexual content on soap operas may be having on adolescents. Yet, the age of those participating in the sexual activity has not previously been analyzed. Modeling theory states that perceived similarity increases likelihood of imitation. (Bandura, 1994) Adolescents are likely to learn from those to whom they feel they are most similar (Harris, 1994). For these reasons, it may be important to add the category of adolescent participation in the sexual act.

Each of the previously mentioned studies contributes to the research on the sexual content of soap operas. Some of these findings need to be updated, and some need to be combined to get a clearer picture of what is actually being portrayed.

There is a need to understand the sexual content of soap operas before we can determine their possible influence. The previously mentioned studies have found an increase in the portrayal of sexual content. It has been found that issues of commitment and "safer sex" are also important to the understanding of sexual content on daytime soap operas. All of this leads to the first research question.

Research Question 1: What is the rate of portrayed references to sexual activity as compared to previous studies in 1979 and $1987 ?$

\section{Learning Theory}

A primary way that people learn behaviors is through modeling. People learn rules that govern specific situations as portrayed by others. "Once they learn the rule, they can use it to judge or generate new instances of behavior that go beyond what 
they have seen or heard" (Bandura, 1994). According to this concept adolescents may learn how to handle themselves in sexual situations through modeling characters on television. Modeling of like characters is the most significant way that soap operas may have an influence on adolescents. Adolescents may in turn use the modeled guidelines to regulate their decisions.

Personal moral restraints about previously learned behavior may also be effected by modeling. Inhibitory or disinhibitory effects of modeled behavior are dependent on three primary factors. First, observers must feel as if they can accomplish the task. Second, effects are dependent on the observers' perceptions of the positive or negative consequences of the action. Finally, the observers must infer that similar consequences may or may not occur if they themselves were involved in the activity (Bandura, 1994).

Models also have the power to activate a particular behavior. This is especially true if the model's actions show that similar actions will bring positive results to the observer (Bandura, 1994). Bandura also points out that advertisers often capitalize on "evidence that similarity to the model enhances modeling."

\section{Cultivation Effect}

Once viewers are "loyal" to a particular show they are generally exposed to a tremendous amount of soap opera style programming. In contrast to other types of narrative programming, daytime soap operas are shown five days per week. Also, the 
style of writing with the "cliff hanger" ending serves to draw viewers to watch the next program.

According to Buerkel-Rothfuss \& Mayes (1981), this type of repeated exposure may influence a person's social construction of reality, or the "cultivation effect." "It is reasonable to assume that heavy viewers of daytime serials would exaggerate the prevalence of soap opera 'problems' in the real world" (BuerkelRothfuss \& Mayes, 1981). Soap opera viewers may perceive that the amount of infidelity and divorce is higher than actual statistics for these categories express. They may also feel that the number of people who contract sexually transmitted diseases is lower than the actual number.

Buerkel-Rothfuss \& Mayes (1981) examined the relationship between exposure to soap operas and viewer perceptions about people and events in the real world. They found that daytime soap opera viewers did perceive increased numbers of certain problems in the world over nonviewers. Greater exposure to television was correlated with perceived greater numbers of men and women who have affairs and have illegitimate children than in real life.

Consistent with other research in cultivation effects (Gerbner et al, 1980 as cited in Buerkel-Rothfuss \& Mayes, 1981) this study of these effects does show a correlation between excessive viewing and a person's perceptions of the world. Many relational activities are portrayed with exaggerated frequency on soap operas. The way they are portrayed may influence the viewer's perception of that activity. 
Adolescent Television Viewing Behavior

Television is on in the home an average of seven hours each day. (Signorielli, 1991) More than $40 \%$ of adolescent's time is spent in leisure activities such as watching television, listening to music and reading magazines (Brown et al, 1994). With this amount of exposure, television has the ability to have a significant influence on the adolescent viewer.

Brown and Walsh-Childers (1994) reported that only $1 / 3$ of adolescents talk to their parents about sex. They also found that only a similar number had "comprehensive" sex education in school. Without information from other sources, adolescents may rely on television for their sexual information.

Daytime soap operas have been criticized as having excessive sexual content. These programs are popular among adolescent girls. Although these girls are in school during most soap opera viewing time, many rush home from school to see the shows that start at 3:00 p.m. (the latest time a daytime soap opera airs on the west coast). Adolescent girls often video record their favorite soap operas to watch either later the same day or on the weekend. The effort adolescent girls put into seeing these programs seems to indicate their significance in the lives of these young viewers. Influence of Sexual Television Programming on Adolescents

With knowledge of the way people learn behaviors and the amount of television viewed by adolescents, it is important to investigate the possibility of a relationship between the viewing of sexual acts on television and the sexual behaviors 
of adolescents. An extensive amount of research has gone into this possible correlation. Courtright and Baran (1980) found that peers and the media are important to the sexual socialization of adolescents. Peers and the media were significantly more important than family. In survey research they found a relationship between media involvement and adolescents' sexual satisfaction. They concluded that media affect individual perceptions of sexual satisfaction. In other words, if viewers feel that their sexual experiences are similar to those on television they will be more satisfied with those experiences.

A correlation has been found between the proportion of sexual programming viewed by adolescents and their sexual activity. Peterson et al (1991) found a significant correlation between heavy viewing of sexual television in 1977 and the initiation of intercourse by 1981 . They also felt that the context in which television is viewed is related to sexual activity. "Television acts more indirectly by teaching, in the absence of other influences, certain values, language and scripts that are consistent with and perhaps encourage sexual activity." Adolescents may behave according to what they see on television without the presence of contradicting influences.

Peterson et al (1991) assert that there are reasons why sexual programming should have an effect on children: "the consistency of sexual messages projected by television programming; the adult nature of most of the programming children watch; children's limited access to countervailing views; and the realism of most television programming." 
According to Peterson et al, social learning theory may explain how television affects sexual behavior. "Television is seen as an increasingly influential agent of socialization that produces its effects through children's propensity to learn by imitation." This notion supports the idea that children may do things because they see them on television.

Additionally, Brown and Newcomer (1991) found that adolescents whose television viewing included a higher number of sexually explicit shows were more likely to have had sexual intercourse in the year prior to the study. In a three phase study they found that over time adolescents who became more sexually active were those who sought out programming with sexual references. It was found that nonvirgin adolescents were also those who most often viewed shows that contain sexual content. This relationship was true regardless of social class and race.

Adolescent males reported watching late night and adult entertainment programs. On the other hand, adolescent girls reported a preference for daytime soap operas (Peterson et al, 1991). These soap operas have been found to have high sexual content when compared to other types of programming (Lowry \& Towles, 1989). Brown and Newcomer (1991) found that the adolescents who preferred this type of programming were also those who were most likely to be sexually active.

Along with commonly cited reasons for watching television, soap opera viewers list sex and romance (Rubin \& Perse, 1987 \& Babrow, 1987). Sex and romance are not generally included in reasons for viewing of other types of 
programming. Typical reasons for viewing include passing time, entertainment, learning and social interaction. However, Babrow (1987) found that sex and romance were primary reasons given for viewing soap operas.

Adolescents view a great deal of highly sexual television programming. The previously mentioned research has shown that this may or may not have an influence on the sexual behavior of adolescents. To understand the full potential of these shows for influence we must first understand how adolescents perceive the sexual content to which they are exposed. To reach this understanding we must answer the second research question.

Research Question 2: How do adolescents perceive the sexual content of daytime soap operas in comparison to adults?

\section{Viewer Involvement}

Of the programs with sexual themes, soap operas are of special significance because of the degree of viewer involvement. Kielwasser and Wolf (1989) found that the immense popularity of soap operas is based on three levels of gratification in the programs. These gratifications, they feel, "facilitate the maintenance and escalation of the viewer-program relationship" (Kielwasser \& Wolf, 1989). Gratifications were categorized by Kielwasser and Wolf as "immediate gratification events, short term gratification events and long term gratification events." Long term gratifications are dependent on establishing a relationship with the program and include the ability to predict what characters will do. To become this deeply involved requires initial 
interest. Initial interest in the program is based on the immediate gratification events. Kielwasser and Wolf characterized immediate gratification events as "heavily sexual and/or confrontational imagery. Therefore, sexual content is an essential component for developing viewer participation and loyalty.

Recent mass communication research (Greenberg \& D'Alessio, 1985; Livingstone, 1989) has pointed out a need to go beyond content to understand the effects of soap operas on their viewers. Effects cannot be fully understood through an investigation of what the viewers are digesting. "Viewers do not necessarily find salient those categories identified by researchers as important" (Livingstone, 1989). Meanings of the soap opera content are often created by the viewer. Livingstone (1989) found that understanding viewers' perceptions of the characters helped to explain the influence of the content.

A better understanding of the way adolescent and adults perceive the soap operas they watch was established through focus group discussions. This gave a deeper understanding of the way they talk about the shows and what they see as significant components of soap operas. Combined with content analysis comparisons, these focus group discussions show what is being seen and what is being understood.

This study updates prior examinations of sexual content on daytime soap operas by investigating verbal references, implied sexual acts and mention of sexually transmitted diseases. In addition, it extends earlier work by analyzing the commitment level and age of those involved in the sexual content. Finally, this study attempts to 
obtain a clearer picture of what adolescents perceive while viewing these shows. This was investigated by conducting adolescent and adult focus groups to see how they talk about soap operas. Also, comparisons were made of adult and adolescent coding of the sexual content on soap operas. 


\section{Chapter III}

\section{Method}

To obtain an understanding of the sexual content of soap operas and how adolescents perceive that content, I video taped a sample of daytime soap operas and I coded these shows to distinguish content. Later, six adolescent females and six adult females coded one potentially controversial episode. The results of the adolescent sample were compared with the adult sample to distinguish adolescent perceptions of sexual content on daytime soap operas. In addition, to gain a better understanding of viewer perspectives, one adolescent and one adult focus group were conducted.

\section{Sample}

A sample was taken of all networks (ABC, $\mathrm{CBS}$, and NBC) from a six month period from March 1 through August 31, 1995. ABC carries three one hour programs and one half hour program. CBS carries three one hour programs. NBC carries two one hour programs. I chose two days per month to tape each network. These days were chosen by me and were interspersed throughout the month. This came to six days each month, a total of 36 days of recorded shows, and a total sample of 78 hours of programming (commercials were taped but will not be coded). This period was picked for researcher convenience. However, as Modleski (1982) points out, soap operas tend to repeat similar story-lines over and over. Therefore, the six month period chosen for this study is not unique or atypical. From the 78 hours of soap opera 
programming 36 hours were selected for coding for this project. Four episodes were randomly selected from each soap opera.

Researcher Coding

The coding system closely followed the example of three previous studies (Lowry and Towles, 1989; Lowry, Love and Kirby, 1981; Silverman, Sprafkin, and Rubinstein, 1979) and their classification of sexual behaviors in terms of verbal references, physical acts and implied acts. I also followed the example of Larson (1991) who analyzed the soap opera All My Children and based her codes on the commitment level of the romantic relationship. Adolescent is a new category which was added to this study.

Erotic touching, as defined by Lowry and Towles, (1989) is "interpersonal touching that had clear sexual overtones, demonstrated or intended to demonstrate sexual love, or aroused or sexual desire." This category includes " 'heavy' kissing, sexually romantic embraces and hugs, sexual caressing or touching of any part of someone else's body, and other similar touching behaviors. It excluded casual handholding, an arm casually around someone's waist or shoulder, a casual 'peck' type of kiss, nonsexual greeting and farewell kisses, parent-child kissing and hugging (unless incest was implied), and other nonsexual touching." If there was any question in my mind whether the touch was erotic enough, it was left out.

Heterosexual intercourse was classified in terms of verbal, implied, or physically depicted acts. According to Lowry \& Towles, “"verbal' references to the 
act of heterosexual intercourse included 'an affair,' 'cheat on me,' 'roll in the hay,' 'shack up with her,' 'unfaithful,' and 'make love.' 'Implied' heterosexual intercourse was coded when a scene depicted the start or end of lovemaking but did not show the physical act itself." A love-making scene was coded each time it was shown, even if the scene was interrupted for a commercial. Although pregnancy implies the act of sexual intercourse, discussions of pregnancy were only coded when the act of making the woman pregnant was directly under discussion.

Sexual acts including implied sexual intercourse and erotic touching were coded at the level of the scene. Verbal references were coded at the level of each individual statement. It is possible for there to be several verbal references to sexual activity in one scene, but no matter the length of the scene or short pauses in erotic touching there was only one visual act coded per scene. The exception to this was, if the couple completely broke apart (no longer touching) during the scene and then came back together within the same scene. In addition, exact verbal references were recorded.

\section{Commitment Level}

Each of these categories (erotic touching, intercourse verbal, intercourse implied, and intercourse physical) were broken down in to subcategories of married, committed but not married, and uncommitted. As in Larson's study (1991) "commitment was assessed by considering the exclusiveness of the relationship..., the 
legal and living arrangements and conversations that revealed the character intentions and feelings." Rape and prostitution were classified as noncommited sexual acts. Pregnancy Prevention/STD Prevention and Contraction

Following the example of Lowry \& Towles (1989), I also used the categories of "pregnancy prevention (talking about, implying, or practicing any form of birth control), sexually transmitted disease prevention (talking about 'safer sex' or implying or actually taking steps to prevent STDs), and sexually transmitted diseases contracted (verbal, implied, or physical depiction of someone who has contracted gonorrhea, syphilis, herpes, AIDS, or other STDs)."

\section{Adolescent Behavior}

Finally, since the potential influence, on adolescents, of viewing sexual acts is the focus of this study, there is a category for adolescent sexual acts. Adolescents are defined as high school students, ranging in age from 13 to 17 years old. This category has not been included in previous studies on the sexual content of soap operas. Given the evidence that people model characters who are perceived as similar, this category seemed significant to an investigation of the influence on adolescents. Adolescents were also broken down into the subcategory of commitment level.

I was the primary coder. To ensure intercoder reliability, a second coder was trained to code $20 \%$ of the programs. The soap operas coded for intercoder reliability were randomly selected from the samples viewed by the primary researcher. The overall level of intercoder agreement was $89 \%$. The most significant difference came 
out of the verbal references to sexual acts ( $82 \%$ intercoder agreement). The primary coder appears to have read more into comments and judged them to be sexual more frequently than the secondary coder.

Pilot Tests

A pilot test was conducted to test the effectiveness of the coding sheet and smoothness of the coding process. One program from each network was randomly selected from the previously recorded episodes and coded based on the categories listed above. In the three programs that were coded for this pilot test, thirteen instances of erotic touching were coded. Three of these instances were between a married couple, ten were between two people in a committed/not married relationship and one involved an adolescent couple. Also in this pilot test, two instances of heterosexual intercourse were observed. Both of these instances were verbal references to sex by noncommited participants. In one case a woman unbuttoned her blouse lower and made the comment, "sex sells."

A pilot test was also run to test the clarity of the instructions for the adult coding vs. adolescent coding experiment. The coder was given the instruction and coding sheets and a video of a one hour soap opera. Without instruction from the author, she read the instructions and completed the coding as expected. Upon completion she was interviewed. She stated that the instructions were easy to understand, as were the definitions of the terms. 
In this particular episode I found two instances of erotic touching between a married couple and five instances of erotic touching between a couple who was committed but not married. For the same episode the pilot test coder found two instances of erotic touching between a married couple and six instances of erotic touching between a couple who was committed but not married.

\section{Subjects}

To obtain a better understanding of the context in which soap operas are viewed, two separate focus groups were held. One group involved four adolescent females and the second involved five adult females. I am acquainted with an adolescent female from a local high school. This subject put me in contact with other adolescent female subjects. The primary criteria for adult females was that they should be between twenty-five and thirty-five years old. This age range helped to separate them significantly from the adolescents, but left them in the primary age group of soap opera viewers (Nielsen, 1995). All of the participants in the adolescent group knew each other. This familiarity was also true of the adult group. Insuring familiarity among participants was an attempt to create a comfortable and "safe" environment for them to discuss openly their views about soap operas.

Prior to choosing subjects and forming focus groups, potential subjects were given a questionnaire which asked them to state which soap operas have characters or plots that they recognize ( see Appendix A). The subjects did not need to watch the show regularly. For example, if the subject had watched the soap opera a couple of 
times and knew some of the characters or if they previously watched the soap on a regular basis, but didn't anymore they would qualify. The show that was watched the most was chosen as the focus soap opera and all subjects who were familiar with that soap opera were invited to participate. The soap opera that was most frequently viewed and subsequently chosen was Days of Our Lives.

To obtain a better understanding of how adolescents perceive the sexual content of soap operas, coding comparisons were made between adolescent and adult female viewers. Six adolescent females and six adult females coded a potentially controversial episode of Days of Our Lives. Adolescent boys were not used because they have been found not to view soap operas as frequently as girls. Also, when boys do watch they have been found to watch for the adventure rather than sexual or romantic content. (Frenier, 1992)

Focus Group and Subject Coding Procedures

Focus groups for adolescents were held in the home of one of the subjects. The adult focus group also met at the home of an adult subject. Once the groups were gathered, the subjects were asked to discuss what was currently happening on Days of Our Lives. The subjects were also encouraged to talk about their favorite characters. The discussion of favorite characters was brought about in hopes of discovering to which characters the subjects related. Subjects were also encouraged to talk about whether they felt the show was realistic or useful and why they watched their favorite soaps. 
Following the guidelines of Morgan (1988), I conducted the groups with a careful attempt to avoid moderator bias. Although I am familiar with the soap operas, I attempted to stay neutral on my feelings about particular story-lines or characters. I also encouraged the subjects to be open because their names would not be revealed in the transcripts and that the tapes would be erased once the transcripts were made. I also told the subjects that there were no right or wrong answers and that I just wanted to know what they thought and felt.

At the end of the focus group subjects were asked to take home one episode of Days of Our Lives and code the episode for sexual content. Subject coders viewed the soap opera separately. This procedure was followed in hopes of avoiding pressure to indicate on their code sheet perceived sexual content because others had done so. Code sheets were provided. These sheets included a demographics questionnaire, an instruction sheet (including definitions of each category) and a coding sheet to indicate viewed sexual content (see Appendix A).

All subjects viewed the same one hour episode of Days of Our Lives. Therefore, all subjects were administered the same stimuli. This was done to increase validity of comparison between adult and adolescent perceptions. The episode chosen for subject coding contained potentially questionable acts of and references to sexual activity. Subjects might find it simple to find outright references to sexual activity. It was thought that the interesting differences between adults and adolescents would most likely rise out of perceived differences in subtle references. 
Analysis

To better understand the sexual content of soap operas and how adolescents perceive them the data were analyzed in several ways. Coded categories were evaluated in terms of overall frequencies and rate per hour. The data were compared to previous studies to assess the trend of sexual content between the 1979,1987 and the current study. In contrast to previous studies the category of not married was divided into committed/not married and noncommited. However, for comparison to previous finding these two categories will be combined into the category of unmarried. In the discussion there is separate mention of the outcomes of each of these categories. The category of adolescent portrayals of sexual content is new to this study. There are no previous findings that can be compared for this category

The focus groups were analyzed with a combination of qualitative and content analysis. Each of the categories used for coding of soap opera episodes was also used to analyze the content of the transcripts taken from each focus group. Qualitative analysis was based on comments relevant to previous literature. An investigation was made to find if the comments of the focus groups confirmed or contradicted previous findings.

Means were calculated to determine differences between adolescent and adult perceptions of the sexual content of the same episode of Days of Our Lives. Erotic touching and verbal references to sexual intercourse were the only categories that applied to this episode. A comparison was made between the adolescents' mean 
perceptions of erotic touching and the adults' perceptions of the same. This same procedure was also followed for a comparison between the adolescents' mean perceptions of verbal references to sexual intercourse and the adults' perceptions of the same.

This is an exploratory study and as such the samples were chosen for convenience. This is also true of previous studies. Therefore, tests of significance would be inappropriate since the coded episodes and both the adult and adolescent samples are samples of convenience and violate the assumptions of a true random sample. 


\section{Chapter IV}

\section{Results}

Research Question 1: What is the rate of portrayed references to sexual activity as compared to previous studies in 1979 and $1987 ?$

Tables 1,2 and 3 present the 1979, 1987 and 1995 rates and frequencies for different types of sexual behaviors. In the present study, there was a total of 223 codable sexual behaviors, or an overall rate per hour of 6.5 . This compares with 7.4 in 1987 and 6.6 in 1979.

Erotic touching between married couples has remain relatively constant at .5 (1979) and .2 (1987) to .8 acts per hour. For unmarried couples erotic touching also remained relatively constant at 2.3 (1979) and 3.9 (1987) to 2.2 acts per hour. In the current study unmarried couples were divided between committed and uncommitted. Committed/not married couples were involved in erotic touching at a rate of 1.4 acts per hour. Uncommitted couples were involved in the same activities at a rate of .8 acts per hour. Erotic touching between teenage partners occurred only once.

Heterosexual Intercourse was portrayed in two ways, verbal reference and visually implied. Verbal references to sexual intercourse between married couples went from .6 (1979) and .1 (1987) to .2 acts per hour. Between unmarried couples verbal references to sexual intercourse occurred at a rate of 2.3 acts per hour; compared to 2.9 (1979) and 2.7 (1987). Among the unmarried couples verbal references to committed sexual intercourse occurred at a rate of .2 acts per hour. On 
the other hand, references to uncommitted sexual intercourse occurred at a rate of 2.1 acts per hour. The majority of the verbal references to uncommitted sexual intercourse were references to extra-marital affairs. Adolescents were involved in 1 act involving verbal references to sexual intercourse.

Visually implied sexual intercourse among married couples occurred at a rate of .2 acts per hour, as compared to .1 acts per hour or total 3 acts (1979) and none (1987). Occurrences of unmarried visually implied intercourse remained the same at .2 acts per hour. Among these unmarried couples involved in visually implied sexual intercourse, no acts involved a committed couple and .2 acts per hour involved uncommitted couples.

Under the category of "safer sex," pregnancy prevention was mentioned once by a college student who said that she wished she had practiced safer sex when she was in high school because then she might not have gotten pregnant. STD prevention was mentioned at a rate of .1 references per hour. STD contracted was mentioned 18 times at a rate of .5 references per hour. (see table 1,2,\&3)

Four episodes of each show were coded; Loving was a half hour show and the rest were one hour shows. Days of Our Lives had the highest amount of sexual references, a total of 46 references in the four hour period. This was followed by All My Children with 35, plus As the World Turns and General Hospital with 33. The rest of the soap operas came in with progressively lower numbers of references per four episodes. Young and the Restless had 23, Guiding Light 20, One Life to Live 19, 
Another World 10 and Loving had only 6 references per four hour period. No correlation was found between ratings and the amount of sex portrayed on the soap operas. This finding implies that increasing sexual content on soap operas does not necessarily produce higher ratings.

The two shows with the highest number of references to sexual activity are aired a 3:00 p.m. This is the time that adolescents are most likely to watch soap operas because of their school schedules. However, this cannot be applied to the U.S. population in general because most of these shows are aired at different times throughout the country. (see table 4)

$\mathrm{ABC}$ was the network with the highest number of sexual acts overall, with 93 . The next highest rate for overall number of sexual acts was CBS, with 76. Finally, NBC had 56 sexual acts for all coded shows. This may be explained by looking at the number of soap operas on each network. $\mathrm{ABC}$ has four soap operas. However, one of the $\mathrm{ABC}$ soap operas is a half hour show and two of those episodes did not have any sexual references. CBS has three soap operas, followed by NBC which has only two soap operas. All the soap operas on CBS and NBC are one hour shows. 
Table 1: Rate of sexual references in 1979,1987 , and 1995

\begin{tabular}{|c|c|c|c|}
\hline Behavior & $1979(n=50)$ & $1987(n=52.5)$ & $1995(n=36)$ \\
\hline \multicolumn{4}{|l|}{ Erotic Touching } \\
\hline Married & .5 & .2 & .8 \\
\hline \multicolumn{4}{|l|}{ Not Married } \\
\hline committed & $\mathbf{n} / \mathbf{a}$ & $\mathrm{n} / \mathrm{a}$ & 1.4 \\
\hline noncommited & $\mathrm{n} / \mathbf{a}$ & $\mathrm{n} / \mathrm{a}$ & .8 \\
\hline Total Not Married & 2.3 & 3.9 & 2.2 \\
\hline Total All Erotic Touching & 2.8 & 4.1 & 3.0 \\
\hline \multicolumn{4}{|l|}{ Heterosexual Intercourse } \\
\hline Married/verbal & .6 & .1 & .2 \\
\hline Married/implied & .1 & .0 & .2 \\
\hline \multicolumn{4}{|l|}{ Not Married/verbal } \\
\hline committed & $\mathrm{n} / \mathrm{a}$ & $\mathrm{n} / \mathrm{a}$ & .2 \\
\hline noncommited & $\mathrm{n} / \mathrm{a}$ & $\mathrm{n} / \mathrm{a}$ & 1.9 \\
\hline Total Not Married/verbal & 2.9 & 2.8 & 2.1 \\
\hline \multicolumn{4}{|l|}{ Not Married/implied } \\
\hline committed & $\mathrm{n} / \mathrm{a}$ & $\mathrm{n} / \mathrm{a}$ & .0 \\
\hline noncommited & $\mathrm{n} / \mathrm{a}$ & $\mathrm{n} / \mathrm{a}$ & .2 \\
\hline Total Not Married/implied & .2 & .2 & .2 \\
\hline Total All Heterosexual Intercourse & 3.8 & 3.1 & 2.7 \\
\hline \multicolumn{4}{|l|}{ Safer Sex } \\
\hline Pregnancy prevention & $\mathrm{n} / \mathrm{a}$ & .0 & .0 \\
\hline STD prevention & $\mathrm{n} / \mathrm{a}$ & .0 & .1 \\
\hline STD contracted & $\mathbf{n} / \mathbf{a}$ & .0 & .5 \\
\hline Total All Safer Sex & $\mathrm{n} / \mathbf{a}$ & .0 & .6 \\
\hline Adolescents & n/a & n/a & 1 \\
\hline Total All Sexual References & 6.6 & 7.4 & 6.5 \\
\hline
\end{tabular}


Table 2: Frequency of sexual references in 1979 and 1987 soap operas

\begin{tabular}{|c|c|c|}
\hline Behavior & 1979 & 1987 \\
\hline \multicolumn{3}{|l|}{ Erotic Touching } \\
\hline Married & 26 & 9 \\
\hline \multicolumn{3}{|l|}{ Not Married } \\
\hline committed & $\mathrm{n} / \mathrm{a}$ & $\mathrm{n} / \mathbf{a}$ \\
\hline noncommited & $\mathrm{n} / \mathrm{a}$ & $\mathrm{n} / \mathrm{a}$ \\
\hline Total Not Married & 117 & 205 \\
\hline Total All Erotic Touching & 143 & 214 \\
\hline \multicolumn{3}{|l|}{ Heterosexual Intercourse } \\
\hline Married/verbal & 29 & 3 \\
\hline Married/implied & 3 & 0 \\
\hline \multicolumn{3}{|l|}{ Not Married/verbal } \\
\hline committed & $\mathrm{n} / \mathrm{a}$ & $\mathrm{n} / \mathrm{a}$ \\
\hline noncommited & $\mathrm{n} / \mathrm{a}$ & $\mathrm{n} / \mathrm{a}$ \\
\hline Total Not Married/verbal & 144 & 146 \\
\hline \multicolumn{3}{|l|}{ Not Married/implied } \\
\hline committed & $\mathrm{n} / \mathrm{a}$ & $\mathrm{n} / \mathrm{a}$ \\
\hline noncommited & $\mathrm{n} / \mathrm{a}$ & $\mathrm{n} / \mathrm{a}$ \\
\hline Total Not Married/implied & 10 & 9 \\
\hline Total All Heterosexual Intercourse & 186 & 158 \\
\hline \multicolumn{3}{|l|}{ Safer Sex } \\
\hline Pregnancy prevention & $\mathrm{n} / \mathrm{a}$ & 0 \\
\hline STD prevention & $\mathrm{n} / \mathrm{a}$ & 0 \\
\hline STD contracted & $\mathrm{n} / \mathrm{a}$ & 0 \\
\hline Total All Safer Sex & $\mathrm{n} / \mathrm{a}$ & 0 \\
\hline \multicolumn{3}{|l|}{ Adolescents } \\
\hline Erotic touching & $\mathrm{n} / \mathrm{a}$ & $\mathbf{n} / \mathbf{a}$ \\
\hline Intercourse/verbal & $\mathrm{n} / \mathrm{a}$ & $\mathrm{n} / \mathrm{a}$ \\
\hline Intercourse/implied & $\mathrm{n} / \mathrm{a}$ & $\mathrm{n} / \mathrm{a}$ \\
\hline Safer Sex & n/a & na \\
\hline Total & 329 & 387 \\
\hline
\end{tabular}


Table 3: Frequency of sexual references in 1995 soap operas

\begin{tabular}{|c|c|}
\hline Behavior & 1995 \\
\hline \multicolumn{2}{|l|}{ Erotic Touching } \\
\hline Married & 30 \\
\hline \multicolumn{2}{|l|}{ Not Married } \\
\hline committed & 46 \\
\hline noncommited & 25 \\
\hline Total Not Married & 71 \\
\hline Total All Erotic Touching & 101 \\
\hline \multicolumn{2}{|l|}{ Heterosexual Intercourse } \\
\hline Married/verbal & 6 \\
\hline Married/implied & 6 \\
\hline \multicolumn{2}{|l|}{ Not Married/verbal } \\
\hline committed & 7 \\
\hline noncommited & 64 \\
\hline Total Not Married/verbal & 71 \\
\hline \multicolumn{2}{|l|}{ Not Married/implied } \\
\hline committed & 3 \\
\hline noncommited & 6 \\
\hline Total Not Married/implied & 9 \\
\hline Total All Heterosexual Intercourse & 92 \\
\hline \multicolumn{2}{|l|}{ Safer Sex } \\
\hline Pregnancy prevention & 1 \\
\hline STD prevention & 5 \\
\hline STD contracted & 18 \\
\hline Total All Safer Sex & 24 \\
\hline \multicolumn{2}{|l|}{ Adolescents } \\
\hline Erotic touching & 1 \\
\hline Intercourse/verbal & 3 \\
\hline Intercourse/implied & 0 \\
\hline Safer Sex & 2 \\
\hline Total All Adolescent References & 6 \\
\hline
\end{tabular}


Table 4: Total count of sexual references for each soap opera

\begin{tabular}{|llll|}
\hline Soap Opera & Total Count & Rating $^{*}$ & Time $^{* *}$ \\
Days of Our Lives (NBC) & 46 & & \\
All My Children (ABC) & 35 & 4 & $3: 00 \mathrm{pm}$ \\
As the World Turns (CBS) & 33 & 2 & $3: 00 \mathrm{pm}$ \\
General Hospital (ABC) & 33 & 6 & $1: 00 \mathrm{pm}$ \\
Young and the Restless (CBS) & 23 & 3 & $2: 00 \mathrm{pm}$ \\
Guiding Light (CBS) & 20 & 1 & $11: 00 \mathrm{am}$ \\
One Life to Live (ABC) & 19 & 7 & $2: 00 \mathrm{pm}$ \\
Another World (NBC) & 10 & 5 & $2: 00 \mathrm{pm}$ \\
Loving (ABC) & 6 & 8 & $2: 00 \mathrm{pm}$ \\
* Ratings based on Nielsen National TV Ratings, 1995 & & $12: 00 \mathrm{pm}$ \\
** Time indicates time soap operas aired in Portland, OR, 1995 & & \\
\hline
\end{tabular}

Research Question 2: How do adolescents perceive the sexual content of daytime soap operas in comparison to adults?

The findings that answer this question are based on a comparison of the content analysis of one episode of Days of Our Lives, coded by adolescent and adult subjects. Significant differences appeared between the adolescent and the adults, primarily in the area of verbal references to sexual intercourse.

I coded this episode prior to subject coding. There were 2 married and 2 noncommited acts of erotic touching. This comes to a total of 4 instances of erotic touching. In the category of heterosexual intercourse, there was one verbal reference to married intercourse. There were also 10 verbal references to noncommited sexual intercourse. This comes to a total of 11 verbal references to heterosexual intercourse.

Perceptions of the commitment level of the characters was not compared. The commitment level of the participants may have been unclear to the subject coders. 
The primary couple participating in the conversation involving sexual verbal references and some erotic touching have had an on again-off again relationship. Some of the subject coders commented that they were not sure about the commitment level for this couple. For this reason, all perceived acts of erotic touching and all perceived verbal references to sexual intercourse were combined.

Six adolescents viewed the same episode of Days of Our Lives. The adolescent subject coders found a mean of 3.5 acts of erotic touching. For verbal references to sexual intercourse, the adolescent mean was 3.8. The range for erotic touching was from 2 to 4 portrayed acts. For verbally implied intercourse the range is from 0 to 11 . One adolescent subject turned eighteen the week before coding this soap opera. Being eighteen brings her slightly out of the defined perimeters of adolescence. This subject found 4 acts of erotic touching and 11 verbal references to sexual intercourse. These findings are similar to the adult subject responses. If this subject, who is not exactly an adolescent, is removed from the adolescent sample they have a mean of 3.4 acts of erotic touching and 2.2 verbal references to sexual intercourse. The variance without the eighteen year old would be the same for erotic touching, but for verbal references to sexual intercourse the range was 0 to 6 .

Six adults viewed the same episode of Days of Our Lives. The adult subject coders found a mean of 3.5 acts of erotic touching. For verbal references to sexual intercourse, the adult mean was 11.2. The range for erotic touching was from 3 to 7 . For verbal references to sexual intercourse the range was from 9 to 13 (see table 5). 


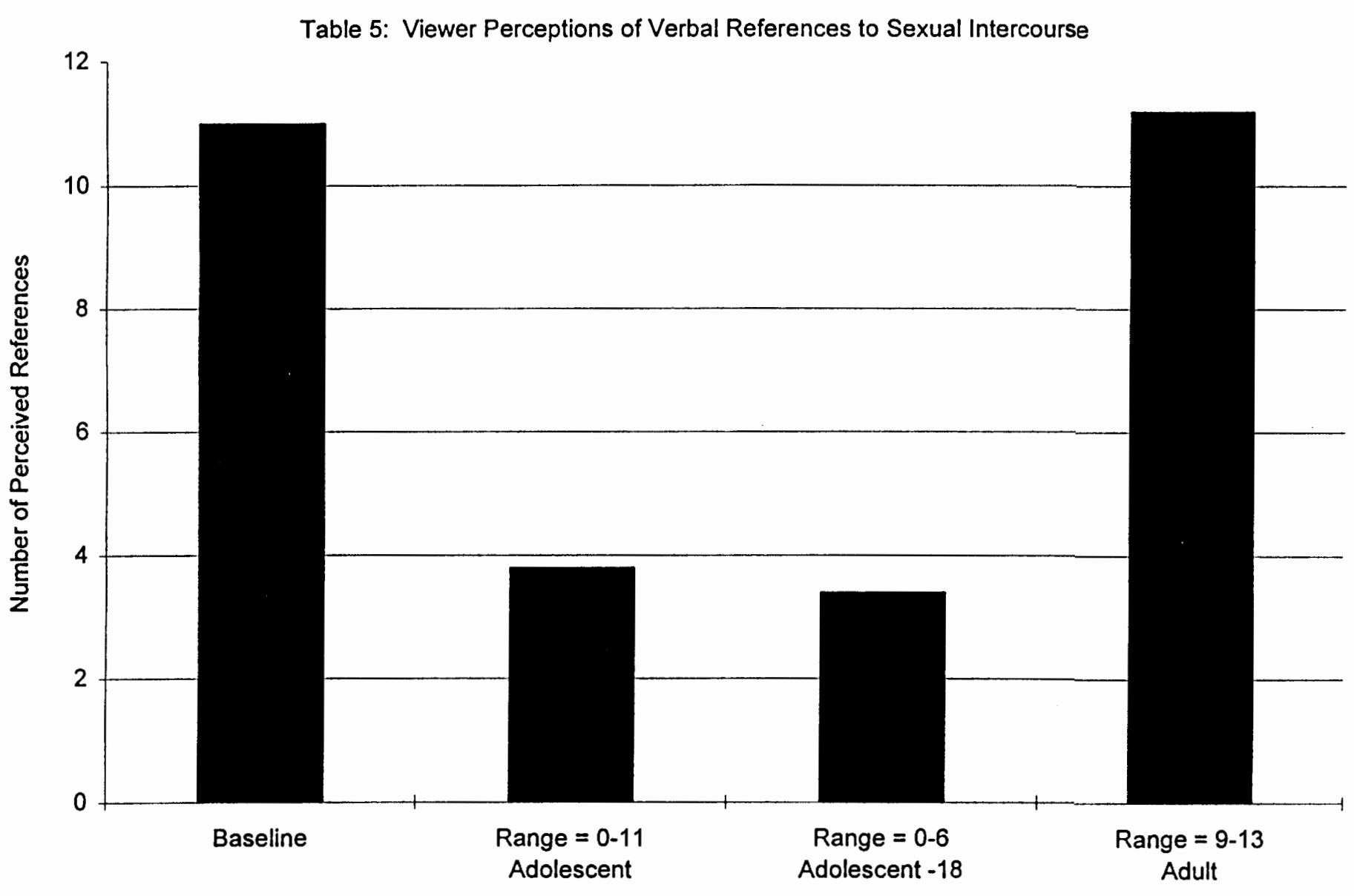


Focus Group Analysis

A content analysis was run on sexual references made by the focus group participants. The adolescent focus group lasted approximately one hour and the adult focus group lasted approximately one and a half hours. For the purpose of validity, only the first hour of the adult focus group was coded for sexual content and compared to the entire one hour of the adolescent focus group. These references were coded in terms of erotic touching, intercourse and "safer sex." As with the coding of the soap opera episodes each verbal reference was coded, even if there were several references within one topic of conversation.

The adolescent focus group participants had 9 sexual references. All of these were references to sexual intercourse. There were no references to erotic touching or "safer sex." In contrast, the adult focus groups had a total of 19 sexual references. These references included: 3 references to erotic touching, 13 references to sexual intercourse and 3 references to "safer sex." 


\section{Chapter V}

\section{Perceptions of Soap Opera Viewing}

Distinct differences and similarities beyond discussion of sexual activity rose out of the focus group discussions of adolescents and adults. Several issues of social learning were raised, such as modeling and inhibitory effects. Viewers also discussed viewing context, reasons for viewing and their perceptions of the sexual activity portrayed on the soaps.

Modeling Theory

Modeling theory is based largely on the notion that the viewer will learn behaviors from characters who they perceive to be similar to themselves. Focus group participants were asked which characters they liked best and to which characters they felt they could relate. There were distinct differences between adolescent and adult reactions to this question.

Adolescent participants said that they felt there were no characters in the soap operas they watched to whom they could relate. They mentioned that there was only one primary character, named Sami, who was close to their age (approx. 19 years old). However, they felt that they could not relate to her because she is "totally weird." This character is best known for drugging her sister's fiancé so he would sleep with her. She has subsequently had a baby as a result of that affair. She also lies and is deceitful in her actions to keep her sister and the man apart. The adolescent focus group participants did mention one secondary character, who is close to their age (also, 
approx. 19 years old) as someone to whom they could relate. One participant said, “maybe Jamie, she's the only one, she's more of a, I mean she doesn't do any of those things. She is always there for her friends and stuff." This character is not on as frequently and is, by soap opera standards, plain looking.

The rest of the characters that the adolescents mentioned liking were adult women who were described as "reasonable, decent people." Dixie Cooney and Brooke English from All My Children were the favorite characters of one girl. She said 'if you compare them, they're more of an actual person than any of the other characters. They're just nice little ladies, that are at home and make lunch for their kids." Another popular character was liked because they felt that she "never gives up." They went on to describe all the troubles she had lived though and yet she still had character.

If these are truly the adolescent's favorite characters it would seem difficult to attribute learning behaviors from these characters to modeling. Other than the secondary character, who is seen infrequently, the favorite characters are women whose life experiences are far removed from that of an adolescent. These are characters from whom adolescents would most likely learn positive behaviors.

The adolescents seem to be looking for role models. They enjoy watching and learning from women they look up to and to whom they would eventually like to be similar. This has serious implications for previous research that is concerned that adolescents are learning negative behaviors from negative characters. This study 
shows that adolescents are more interested in characters they see as "responsible" adults.

Modeled behavior can have inhibitory and disinhibitory effects on the observer. The first stipulation put forth by Bandura (1994) for inhibition or disinhibition is that the observer must feel that they can accomplish the task being performed by the model. The behavior of the character Sami, who is closest to the adolescent subjects' age, would seem to be inhibitory. Both the adolescent and adult participants discussed how ridiculous and impossible it would be for her to drug someone to get them to sleep with her and that he would not remember anything. Therefore, the sexual behavior of the one character who is similar to them would most likely not influence the adolescent viewer's behavior.

The adults on the other hand, had far different criteria for determining their favorite characters. The majority of the characters that the adults felt that they could relate to, were in their mid twenties to early thirties. This is the same age range of the adult focus group. Additionally, the adults described their favorite characters in pairs. All of the adults either liked Kari and Austin or Bo and Hope. Both of these pairs are current romantic partners, who are dealing with relationship development and maintenance issues.

The adults seemed to feel that they were also likely to be attracted to the storyline rather than just to the characters. For example one woman stated that "it's kind of hard [to say which I like best] because we seem to like the characters 
pertaining to their storyline." Based on their current favorite characters they seem to like characters who they see as similar and who are involved in romantic issues.

Learning behaviors through modeling similar characters seems to be more likely to occur among adult viewers of soap operas. Each of the adult participants was in a romantic relationship. Therefore, they chose as their favorite characters, people who were their same age and were possibly experiencing similar issues and experiences involved in a romantic relationship.

Perceived Usefulness of Soap Operas

Distinct differences also emerged when the focus group participants were asked if they felt that the shows were useful or realistic. The adolescent group stated that the shows were completely unrealistic. They went on to describe all of the storylines that were strange and unusual. One adolescent participant stated that soap operas were "not at all realistic, it's just, I mean there are some parts that you can relate to but, you know, drugging people, you know, getting them into bed, having their kid and stuff, that's not what real people do." Other participants added to this: "framing them with the police, potions that make you seem dead, coming back after twenty years saying you were lost in some country in the Middle East or something, captured in a strange prison." The adolescents also commented on the fact that soap operas never deal with teen issues, like SAT's and the prom.

Adults, on the other hand, listed several reasons they felt soap operas were realistic. They described how easy it was to get involved with what the characters 
were experiencing. In one example, an adult participant described how she became both deeply involved in the storyline and how she used the show in her everyday life:

JO: Like for me, like this is a totally true example. Like I had to get out of work last week "cause I had an interview. And instead of just saying I had an interview, I said a friend of the family had a stroke. [a character on the show recently had a stroke]

JE: And his name was what.

JO: So she asks me out of the blue what is his name and I could not think of anything else and before I could even stop myself, I said, "Oh Victor." And for me it's like what if I go back on Monday and she says, "nice try Victor didn't die." I was like, and for me, I was like "what am I doing?" I just totally coulda just said I have an interview for a real job, this is a temporary agency that I work for. I mean it would be no problem for me to say I had a damn interview but, no instead, I choke. I said I had to go take care of the kids, I have to be there because this man had a stroke.

The adult participants also felt that the show was useful in helping viewers who were going through experiences similar to those of the soap opera characters. One example of just such a storyline was of a woman whose husband wanted her to quit her job. He wanted her to quit for two reasons. First, she was a police officer and he thought it was too dangerous. Secondly, he wanted her to stay home and be a mother to their son. The adult participants felt that there might be women who were dealing with the same issue at home.

Other ways that soap operas were seen as useful were also pointed out. One adult participant said that although it may not be the best model of romantic relationships, it might give viewers a reference point on which to base romantic relationships. The others agreed that the soap opera relationships might at least give 
viewers ideas for dealing with their own relationships. Also, they felt that the show gave them ideas for fashions, including, hair, make-up and clothing.

Interaction With Characters

The fact that viewers get involved with the characters on the show through parasocial interaction was apparent in the responses of the participants of both adolescent and adult focus groups. Parasocial interaction can be defined as a onesided friendship between the viewer and the television character. (Perse \& Rubin, 1989) The subjects often discussed the characters as they would their friends. Three of the adults got into a discussion of how this can happen:

JA: Like somebody will be telling a story about something and I go, "oh that happened to, oh ya," then it totally hits you.

JO: It's totally from Days and oh yes that happened to my friend. You know. It's from Days of Our Lives and you get mixed up for a minute. It's hard to cross over.

JA: No, wait it's a TV show.

$\mathrm{K}$ : Oh, it's like something that happened in my life.

JO: Ya, or like you think you identify, like you think you totally know that person.

Occasionally the participants referred to the soap opera characters by their "real life" names. However, usually the participants of each group referred to the characters on the show by their character names rather than their real life names. They also made statements of feeling toward the characters: "I hate Sami," "She must die," 
or "Vivianne is such a bitch." All of these are examples of how the soap opera viewer does become "personally" involved with the characters.

The fact that the subjects did this is not surprising. The actor losing their identity in the character is orchestrated by the producers of soap operas. Unlike film stars, soap opera actors are promoted with their character's name. Butler (1991) points out that "besides the genre's low status in the acting hierarchy, the genre itself has long operated to efface the presence of the performer." This down-play of the actors is purposely done to decrease disruption if the actor leaves. Soap opera producers can and often do replace the person with another actor with little or no acknowledgment of the switch. Losing a particular actor has little influence on the dynamics of the show. If the audience does not know the character as an actor they are less likely to be upset when that actor leaves, as long as the character remains.

Reasons for Viewing

When asked why they watched the soap opera they do, one of the reasons given by adult participants was that most of the people they knew watched the same show. Although Days of Our Lives is the number 4 rated soap opera overall, one adult participant said "I think a lot of it, it's like Days 'cause I feel it's like a total connection with the most of any other soap that I've noticed. Like with any person, if they're gonna watch any soap opera it's like nine times out of ten it's Days of Our Lives." 
The adult women went on to discuss how they loved getting together and talking about what is happening on the show. Fine, (1981) in her study of soap opera conversations, points out that soap operas often give viewers something to talk about with others. When I arrived to conduct the focus group, they met me at the door, telling me to hurry up because they were "dying" to talk about the show. They had forced themselves to talk about other things so they would have plenty to say when I arrived.

The adolescents did not give this as a reason they liked their favorite show. However, they did mention that they talk to their friends about the preceding day's soap opera episode, when they get to school. They mentioned that they talk about the shows in class and that classmates, primarily boys, looked at them strangely when they do this. They also mentioned hearing other groups of girls talking about soap operas. "First period, this morning, we were like having a discussion about Sami and Austin and Kari and like what's going on now."

The reason for watching a particular show, that was unanimous among both adolescent and adult women, was that they watched the show because it was the show their mothers watched while they were growing up. They stated that when they got home from school that the soap opera was on everyday. One girl stated that now that her mother works late, she watches it by herself. However, if she has any questions about the history of a character she asks her mother. This same girl also stated that her mother will often ask her, while sitting around the table for dinner, what is happening 
on the show. One adolescent said that her mother asks her to tape the show if she could not be home to see it.

In a society where families are often spread all over the country, soap opera characters could easily become replacements for missing families. Para-communities could be formed by soap opera viewers. Characters of the shows can become like friends through parasocial interaction. This process is likely extended into the entire cast of the show becoming an extended family of sorts. The example of the adolescent girl who discussed the characters of the soap opera with her mother is reminiscent of the way they might talk about family members.

\section{Similarities of Adolescent and Adult Experiences}

There were some group qualities that were consistent among both adolescent and adult focus group participants. In a qualitative analysis of the viewing behavior of college students in a community viewing area, Lemish (1985) found that when a group of soap opera viewers forms, a leader arises. The leader is described as a person who has three qualities: "knowledge about the program, willingness to share it, and enthusiasm for doing so." The leader is also the person that others turn to if they have questions about previous plots or characters.

Within both adolescent and adult focus groups a leader became distinctive early in the session. In each case, the leader was the person who answered questions that the others did not know. They stood out because the had a more in-depth knowledge of the show's history. Additionally, in each group the other members 
commented on the knowledge of the leader. Comments were made about the leaders such as, "woaw, you really get into this." Outsiders might make that comment about all of the group leaders, but within these groups the leader did stand out significantly. Another viewer quality that became apparent in both the adolescent and the adult group was projecting what the characters would do next. Although projecting did occur in both groups, the adults did so with greater frequency. Kielwasser and Wolf (1989) described the ability to predict what characters will do as a quality of a person who has establish a long-term relationship with the soap opera and its characters. One adult said "it's like you live to like guess what they're gonna do." The fact that the adults predicted future storylines and character activity may be attributed to the fact that they had been viewing the soap opera longer than the adolescents. The adults have more historical information on which to base their projections.

The ability to predict the future behavior of the characters is also a characteristic of a "leader" in a soap opera viewing situation (Lemish, 1985). In the adolescent group the only participant who predicted future behavior was the "leader." In the adult group, all of the participants were involved in predicting. However, the primary predictor in the adult group was the "leader." She is the person who said she "lived" to guess. 
Perspectives of Sex on the Soaps

The participants were not specifically asked what they thought of the sexual activity on the soap operas they watch. The purpose of this was to explore the references to sexual behavior that came up naturally in the conversation. References did arise out of both the adolescent and the adult focus group discussions.

All adolescent references were to heterosexual intercourse, there were no mentions of erotic touching or "safer sex." Adolescent references to sexual behavior were negative. In each case the adolescents negatively described the situation and/or the person involved in the sexual activity. Out of their conversations, they discussed that one man who had an affair was left by his wife, another was killed off after he had an affair with his wife's mother. They seemed resigned to the fact that affairs were just an unavoidable fact. One girl stated, "society today, I mean the divorce rate is like over $50 \%$ and um soap operas just exist that way. That's what it is, relationships starting and ending and people cheating on each other." The adolescents also spoke of the shows negatively when describing some of the characters sexual activity. A participant said that after a male character had a "fling" with his girlfriend's best friend, "the show went downhill from there."

Finally, when I was demonstrating the subject coding process, they said that the sex scenes on the shows were "so dumb." They mentioned a scene where the characters rubbed an ice cube all over each other. The adolescents negative attitude 
toward the sexual activity on soap operas would seem to indicate a negative potential for influence.

Adult perceptions of the sexual activity on soap operas was distinctly different from that of the adolescents. The adult discussion of sex was much more casual and graphic. Mentions were made of erotic touching, sexual intercourse and AIDS. The references to erotic touching came forward in a discussion of how much they hated the fact that a male character was actually kissing a female character that they all seemed to dislike.

Sexual intercourse was described in many different contexts. Like the adolescents, the adults discussed the scene with the ice cube. However, in contrast the adults were discussing how hairy the body of the man was and made several exclamations of distaste. This distaste was for the man's body, not the act of rubbing an ice cube all over each other.

The adults made six references to rape through out their discussion of the soap opera history. Often, when they were describing why a male character had left the show, they mentioned that he had raped one of the female characters. They gave this as an explanation as to why one male character had been "killed off."

Two interesting topics came up in the adult discussion of the soap operas. One of these topics came out of discussion about how impossible it would be to drug someone to sleep with you and then have them not remember (this is a current storyline). Out of this conversation, one adult female said the she thinks they should 
have a porno day, and mentioned that she and her friend "always say how hard we would laugh." Although she was not serious in this suggestion, it is an example of how much more comfortable the adults were with the topic of sex.

The other interesting topic, related to sex, that came out of the adult focus group discussion was about the male characters of the show. The adult participants got into a heated discussion of who was the best looking man on the show. They exclaimed over the way one character looked without his shirt. They also went on to describe what they would do if any of their favorite men came to their front door. This discussion was also obviously not to be taken seriously. However, it is another example of the difference between the adult's and adolescent's comfort level with sexuality.

Adolescent and adult soap opera viewers seem to have some distinct differences in they way the perceive and relate to soap opera storylines and characters. Adolescents do not seem to relate to the characters. Based on their comments they seem to watch soap operas out of habit. The reason they seem to watch is to view the relationships of the characters. However, once that relationship moves to a sexual level, they seem to lose interest. This suggests that the sexual content may not have the influence on adolescents that many critics were concerned about.

Adults, on the other hand, seem to relate to most of the characters and storylines. They also take interest in all aspects of the relationship. The sexual activity of the romantic partners is not their primary interest. They seem to be 
interested in the way the characters develop and maintain romantic relationships.

However, they seem to accept the sexual activity as a natural and necessary

progression of romantic relationships. 


\section{Chapter VI}

\section{Discussion}

Content analysis cannot make a direct statement about the effects of television content. It only gives us an idea of what someone might learn from the content. This discussion will explain what could potentially be the impact of sexual programming on soap opera viewers, with a special look at the potential influence on adolescent females. It will also describe the significance of adult versus adolescent perceptions of sexual content on daytime soap operas.

\section{Erotic Touching}

Erotic touching among married couples has changed very little from previous studies. The continued low level of married erotic touching seems to be going against a suggested trend toward more traditional roles for women. Susan Faludi's Backlash (1991) discusses the ways that women are being tricked into believing that there is a trend toward traditional roles for women. She illustrates her point through the description of several articles that were published in the late eighties and early nineties, in magazines such as Time and Newsweek. These articles discussed the "fact" that women were unsatisfied with their careers. Women were leaving their careers in droves to return to their homes, where they belonged. These assertions are not based on fact. Statistical evidence showed that women were staying in the workplace and were becoming increasingly satisfied. 
However unfounded, the idea that women were and should "go home" was showing up in the media. Reaction to sitcom character Murphy Brown having a baby out of wedlock is an example. Vice President Quayle made a call for a "return to family values" and targeted the television show Murphy Brown as an example of the lack of morality in media and society. "Family values" became the buzz word in the media for several months after.

In relationship to this study, if the idea that women were heading home in droves and assuming more traditional roles was true there would likely have been an increase in the portrayal of erotic touching among married couples and a decrease in erotic touching for non-married couples. What did happen is that more portrayals of erotic touching were among unmarried couples.

\section{Commitment Level}

Although erotic touching is not the predominant form of sexual content, couples involved in this activity are for the most part committed. Similar to the findings of Larson, (1991) instances of erotic touching involved primarily married or committed couples. Of the 101 acts of erotic touching, only 30 involved married couples. However, 46 acts were between committed but unmarried partners. This comes to a total of 76 acts of erotic touching between married or committed couples. Less than one quarter of the acts of erotic touching were outside of a commitment.

Visual references to sexual intercourse was also higher for married/committed couples. For the entire sample there were fifteen occurrences of visually implied 
sexual intercourse. Nearly two-thirds (9) of the acts of visually implied sexual intercourse were between couples who were either married or involved in committed relationships.

As the World Turns was the only show that portrayed noncommited implied sexual acts. This category was portrayed by showing a couple in bed, either before or after they have had sexual intercourse. Larson (1991) found in her study of the commitment levels of those involved in sexual activity that those couples who were involved in noncommited intercourse suffered negative consequences. In this study there were five portrayals of implied intercourse. All of these portrayals involved the same couple. This same couple was portrayed in bed, in two separate episodes, in different months. The woman was concerned that if her soon to be ex-husband found out she was sleeping with this younger man, he would get custody of the kids. The man suffered because he could not have the normal, out in the open type of relationship that he wanted.

This trend toward negative consequences for noncommited sexual involvement does not hold true for erotic touching. Non-committed couples who kissed passionately did not always suffer negative consequences. Some of these interludes eventually led to a relationship in later episodes, some of them were dreams and some were acted out in a dance that was performed on stage. However, in one episode that the erotic touching involved noncommited erotic touching, the husband of the woman walked in and found them in an embrace. Although negative 
consequences do not occur for all those involved in noncommited erotic touching, erotic touching which involves deception or "wrong" behavior does seem to lead to negative consequences.

Modeling theory may explain the influence of these negative consequences to soap opera characters. Inhibitory or disinhibitory effects on personal moral restraints about learned behavior may be affected by modeling. The observer of the modeled behavior must feel that they can accomplish the task, perceive positive or negative consequences and believe that similar consequences may or may not occur for themselves. The coded soap operas seem to be modeling negative consequences for sexual intercourse among noncommited couples and for couples who are involve in erotic touching when it is deceptive to either a person in the couple or to an innocent party outside the noncommited relationship.

Aggressive Acts

There were six portrayals of aggressive erotic touching. Aggressive erotic touching is defined as one member of the couple physically forcing the behavior on the other member. Five of these portrayals of erotic aggressive touching were in one episode of Days of Our Lives. The servant of the devil, in the form of a man, tried to coax a woman who he wanted to possess out of the church by hurting her daughter. However, her daughter was not really there. The demon made her appear to be there while he proceeded to forcibly kiss and grope her. 
The other portrayal of aggressive erotic touching was of a woman walking alone on a dock then being attacked by a strange man. She struggled to get away as he tried to kiss her and knocked her to the ground. Another strange man came along and beat up the man who was attempting to rape the woman.

Both of these portrayals of aggressive sexual behavior have a potentially inhibitory influence on someone who may learn from the portrayed behavior. In the portrayal of the demon possessed man, learning of aggressive behavior is not likely to occur. This situation is not realistic. For learning to occur, a situation must seem likely to happen to the viewer who would potentially model the behavior. Learning of aggressive erotic touching is also not likely to occur from the portrayal of the woman being attached. The aggressive male suffered negative consequences when he was beaten up by another male.

\section{Heterosexual Intercourse}

Heterosexual intercourse is portrayed at nearly the same frequency as erotic touching. There were 92 acts of intercourse and 101 acts of touching. However, of the 92 heterosexual intercourse acts, 77 were verbal references. The emphasis on verbal references poses an interesting question about the reason people enjoy watching soap operas. Are people more interested in what the characters are talking about rather than what they are doing?

Due to the lack of action, when compared to other types of television programming, verbal communication is the most significant part of the soap opera 
storyline. "Talk is the mode by which soap opera relationships are created, thrive and die" (Alexander, 1985). As in real life, soap opera conversations form the foundation for relationships. Fine (1981) points out that the predominance of talk in soap operas is often criticized as one of the major negative qualities. Soap operas are all talk and no action. Others feel that this is what makes the soap opera so similar to real life. In her study of soap opera conversations, Fine (1981) found that the predominant topics of conversation in these programs are similar to the topics used in real life conversations. "Soap opera conversations frequently discuss marriage, family, romantic relationships, professional relationships, personalities, health...." (Fine, 1981)

If soap opera conversations are similar to everyday conversations, it may lead the viewer to believe that the things that are said are realistic and common. Most of the verbal references to sexual behavior in this study were noncommited references. These were largely references to extra-marital affairs. However, Days of Our Lives had two episodes with several verbal references to sexual activity that were abnormal to everyday life situations. In one episode, the servant of the devil possessed a woman and tried to convince a priest to sleep with her. Several comments along the lines of "take me," were made. Although, out of context, the verbal references were not abnormal to everyday conversation, the fact that the woman was possessed is abnormal. The other episode had two extensive conversations about how a young woman had drugged her sister's fiancé, seduced him and was pregnant as a result. As 
before, the verbal references themselves were not abnormal, but drugging a person to get them to have sex is not a typical occurrence.

One of the conditions for learning through modeling is that the viewer of the action must feel that the action is possible for them to accomplish. As it is not likely that the average television viewer will come in contact with a devil possessed woman or would drug someone to sleep with them, these conversations, though highly sexual, are not likely to encourage the type of sexual behavior described. However, if a viewer were inclined to want to drug someone or felt they could, they would see that the young woman suffered negative consequences in subsequent episodes.

Other research has investigated the significance of the amount of talk in soap operas. In a study of adolescent's soap opera viewing habits and perceptions of relationships, Alexander (1985) found a correlation between soap opera viewing motivations and perceived importance of talk to relationships. For those adolescents who viewed soap operas for reasons of entertainment or avoidance, the relationship between exposure to soap operas and talk was positive. Although Alexander's study addresses the issue of talk in general, it seems to give some evidence for the significance of talk to the adolescent's experience of soap operas viewing.

Another explanation for the importance of talk may be found in the research of parasocial relationships. Research into parasocial relationships may shed some light on why verbal references to sexual intercourse are greater than visually implied 
intercourse. Viewers often form relationships with television characters similar to interpersonal relationships they form with people they meet in their everyday lives.

One aspect of parasocial interactions involves uncertainty reduction theory. Although parasocial interaction has often been attributed to extensive exposure to television, Perse \& Rubin (1989) seem to think that this form of interaction rises out of a need to reduce uncertainty. When people are in situations that are unfamiliar, they look for ways to increase familiarity and ease tension. The primary method of uncertainty reduction is through conversation (Berger \& Calabrese, 1975). Soap opera viewers may become more attached to the shows and their characters because of the amount of verbal interaction. The verbal interaction helps the viewers to learn more about the characters and therefore, reduce uncertainty and awkwardness. "Safer Sex"

The most significant change from previous studies is an increase in the category of "safer sex." Although the overall rate was only .6 (24 acts), each of the subcategories (pregnancy prevention, STD prevention and STD contracted) was represented.

Both pregnancy prevention and STD prevention were verbal references, rather than visually implied. In addition, all instances of prevention of pregnancy or STD's, the character was saying they wished they has practiced "safer sex." For example, on The Young and the Restless, a female college student was discussing how she had become pregnant when she was in high school. She mentioned that it was their first 
time and she didn't think it would happen to her. Also, on an episode of As the World Turns, a sister was discussing with her brother the sexual behavior of his previous partner. She mentioned that his partner had been promiscuous and that she "doubts she practiced safe sex." His sister also mentioned that he should think about being "tested." AIDS was implied, but not stated outright. Again, this is an example how "safer sex" was mentioned in the past tense, implying that "safer sex" should have been practiced, but wasn't.

By using past tense references to "safer sex," soap opera writers seem to be using the strategy of "fear appeals" to teach the viewers a lesson about "safer sex" practices. Each of the storylines about unwanted pregnancy or STD's was a description of the negative consequences of not having practiced "safer sex." Early fear appeal literature (Dollard \& Miller, 1950 cited in, Beck \& Frankel, 1981) described induced fear as a technique for "driving" people to take action to prevent the portrayed consequence. However, they found that this simplistic approach was not always effective, because the fear would eventually subside.

Recent studies of fear appeals have gone beyond this simple explanation to find a solution. Beck and Frankel (1981) discuss the importance of response and personal efficacy in the effectiveness of fear appeals. This relates to the effectiveness of the recommended plan of action in terms of "its perceived utility in controlling the threat (response efficacy) and of their ability to perform it (personal efficacy)" (Beck and Frankel, 1981). Therefore, fear appeal seems to be effective as long as it is 
backed-up with effective and accomplishable threat-control techniques. People must first be informed of the threat by showing that it is real and will happen if appropriate actions are not taken and then they must be informed of appropriate actions for prevention.

During the time-frame of this study, General Hospital was running an AIDS storyline. A young man in his early to mid twenties contracted HIV. In the episode that he discovered that he had the infection, he discussed how he thought he may have contracted HIV. He said that he had been in a relationship with a woman whom he knew was a drug user. This was at a time when he was living on the streets; before he had been taken in by a family on the show. He said that he was stupid and didn't practice "safer sex," by using a condom, when he was in the relationship with this woman. In a later episode, when it came out to his friends and family that he had "full-blown AIDS," they talked about how they couldn't believe that anyone would not practice "safer sex."

Of the four episodes of General Hospital that were coded for this study, three dealt with the issue of AIDS. The episode that did not, aired before this young man found out that he had contracted HIV. As was mentioned previously, one episode dealt with how he found out he was HIV positive. The next episode dealt with how his present girlfriend was dealing with the situation. Although she had already been tested and found HIV negative, she was concerned that maybe she was HIV positive anyway and it just hadn't show up on the first test. The third episode that dealt with 
HIV, was devoted entirely to an AIDS benefit event. The episode began in a ballroom at an AIDS benefit. The young man with AIDS was telling a group of his friends that he had the disease. The rest of the episode was situated at this benefit, but other topics were dealt with. For example, a couple who was having marital problems discussed what they should do to save their marriage. Although other conversations and events were portrayed, the issue of AIDS was constantly in the background, and the topic of several conversations. At one point, an adult woman said to her husband "can you imagine being a teenager in a world where sexual experimentation could mean death?" Most of the conversations dealing with the topic of AIDS were discussions about how horrible it was that the young man with the disease was going to die. Other conversations dealt with wondering how his family and friends were coping, primarily his girlfriend. Only a few conversations dealt with how to prevent the disease. In one of these conversations one man said, "I didn't realize he was gay." Another said to him, "don't be stupid, you don't have to be gay to get AIDS. Heterosexuals can get it just as easily." Others said that they couldn't believe people would have unprotected sex.

One other soap opera dealt with the topic of AIDS within the time-frame of this study. From the sample, one episode of As the World Turns had three references to AIDS. All of these references came up in a conversation between a teenage boy and girl. The boy was telling the girl how his mother had contracted the disease. By this episode the mother had already died of AIDS, which she had contracted when she was 
raped. The girl told him that when she found out that his mother had died of AIDS, she assumed that he had it too. He told her that it was normal and that he had to quit football because none the guys would go near him. This episode discussed the important issue of how to deal with AIDS victims. However, it does not deal with the issue of prevention.

Although the conversations on General Hospital did cover response efficacy (that anyone can get AIDS) and personal efficacy (that it was preventable with condom use), they were minimal in relation to the amount of "fear." Soap opera writers and producers should be credited for their increased consciousness of the need for "safer sex" through AIDS storylines. However, if current fear appeal literature (Beck \& Frankel, 1981) is correct, these writers and producers may need to rethink the way they are presenting these storylines, if they are to be effective. This may be difficult to do while keeping the show interesting.

Adolescent portrayals of sexual references were minimal. Modeling the behavior of characters who adolescent viewers see as similar does not seem to be an issue. The references to adolescent sexual behavior that were portrayed were either innocent or the people involved suffered negative consequences. The one portrayal of erotic touching involved the first kiss of an adolescent couple. It may be stretching the definition to call it erotic, but it was more than a casual "peck." Two of the verbal reference to sexual intercourse were part of a conversation that involved a college student describing having sex when she was in high school with a boy she "thought" 
loved her. She became pregnant as a result and gave the baby up for adoption. At the time of the conversation, she was afraid that her current boyfriend would find out that she was not the virgin he thought she was. This conversation also involved references to not practicing "safer sex." The other adolescent reference to sexual intercourse was describe earlier. It was a reference to the fact that being a sexually experimenting teenager could lead to death. All of these negative references to adolescent-involved sexual activity will most likely inhibit modeling of such behavior.

What Do Adolescents Hear?

Previous research dealing with television's influence on adolescents has shown a correlation between viewing sexually explicit television and early initiation of sexual intercourse. The present study brings forward many questions about the significance of these findings. Sexually explicit television will most likely not influence adolescents significantly and may require far less concern than it has been given.

From the content analysis comparison, it would seem that adolescents do not hear verbal references to sexual intercourse that are portrayed on soap operas. They did not however, have a problem noting visible references to sexual activity. Adolescents and adults reported seeing similar numbers of erotic touching. Although visible acts were perceived by the adolescents, verbal references seemed to slip by unnoticed. The adolescents did not find nearly the amount of verbal references that the adult subjects found. If adolescents do not hear or register verbal references to sexual intercourse, they will not learn how to talk about their own sexual activity. It 
could be beneficial for adolescents to learn the way that people talk about sex so that they discuss it with their partners rather than just doing it.

The findings that the adolescent females do not hear the sexual content of soap operas support those of Brown et al (1994). They found that often, adolescent girls were uninterested and seemed to ignore sexual content in the media. "Even with prodding, these girls preferred not talking or thinking about sex...." It appears that the girls in the present study feel the same way about sexual content in the media.

Brown et al (1994) felt that this disinterest in the sexual content of mass media may be related to the girls' sexual experiences. The girls who were found to be disinterested in sex were the youngest and least sexually experienced. Sexual content may be irrelevant and a waste of time to girls who do not have sexual experience and therefore cannot relate. This may be the cause of the low level of recognition of verbal references to sexual intercourse for the adolescents in this study.

The fact that adolescents do not hear the verbal references to sexual intercourse may also speak to the way they use the shows. During the adolescent focus group some of the girls did other things when someone else was talking. One girl pulled out a magazine and leafed through it. Another girl got up and went to the kitchen for something to drink. The girls are likely to do similar things while watching soap operas. They may be especially likely to do this if the show is focusing on things the do not find interesting or to which they cannot relate. 
On the other hand, the adults of this study were all involved in romantic relationships. They were either married or in long-term relationships. The adults, who have had sexual experiences, saw and heard within one or two acts, all references to sexual activity portrayed on the sample episode. The more accurate notation of sexual references given by the adults would seem to support the relationship between sexual experience and perceptions of sexual activity. Those subjects who were young and less likely to be sexually experienced heard fewer references to sexual intercourse than subjects with more sexual experience.

The fact that adolescents do not seem to attend to verbal references to sexual intercourse is significant for two primary reason. First, the content analysis portion of this study showed that verbal references are a primary way that sexual intercourse is portrayed on daytime soap operas. If adolescents do not noticed the verbal references, it is likely that they are not receiving much information about sexual intercourse from viewing these shows.

Another concern that comes out of finding that adolescents do not attend to verbal references is for the impact that this has on issues of "safer sex." This study found only verbal references to the need to be sexually responsible. There were no references to "safer sex," in the heat of the moment, before intercourse occurred. The soap opera coded by adolescents did not have any references to "safer sex." However, it is likely that they would have ignored it if it had. 
The other significance of adolescents inattention to verbal references to sexual intercourse is the impact it has on the findings of previous studies. Researchers who have previously conducted content analysis of soap operas were concerned that the amount of sexual content would influence adolescent behavior. However, it is apparent that the amount of sexual content they saw in their coding process was not what adolescents see when they are viewing soap operas. Therefore, to gain an accurate picture of what content the adolescents may be influenced by, we must know to what content they are attending.

\section{Study Limitations}

As with any study, this study had limitations that have possible implications to the findings. The first of these limitations is the sample size of the adolescent versus adult comparison of viewing perceptions of sexual content. This study had six subjects from each group. A sample size of about fifteen subjects from each group would increase our confidence in the findings. Also, it is difficult to determine the level of social desirability involved in the adolescents' comments made during the focus group discussions.

\section{Recommendations for Future Study}

An analysis of the motivations of the characters for having sex may be beneficial for future study. Determining the motivations of the characters may help to determine, more specifically, what viewers are learning about sexual activity and morality/promiscuity. Content analysis shows how much and what kind of sexual acts 
are being portrayed. Understanding motivations would give an idea of what viewers might be learning about the reasons the characters on soap operas are having sex or not having sex, as the case may be.

It may also be interesting to run this study on nighttime soap operas. Some of these shows are targeted to a younger audience. Shows such as Beverly Hills, 90210 and Melrose Place often portray characters who are high school and college age. These characters are also dealing with issues more relevant to teens. Issues such as: virginity, parental abuse, and drug addiction.

If adolescents are asked to code perceived sexual content in future studies it may be beneficial to ask them to write each verbal reference they hear. This will tell us more precisely what they are hearing, which will help us to understand the possible influence of sexual content on adolescent viewers.

\section{Summary of Findings}

This study has shown that the amount of sexual content of daytime soap operas has remained relatively steady since the mid-80's. The only significant change seems to be in the portrayal of "safer sex." An increase was found in the portrayal of "safer sex" which may prove that public concern is acknowledged by soap opera script writers.

The difference between adolescent and adult perceptions raises serious questions about previous correlation studies between television viewing and the initiation of sexual activity, and has significant implications for the possible influence 
this programming has on adolescents. In this study it was found that adolescents and adults have distinctly different perceptions of soap opera content. Each group talks about soap operas differently and relates to the characters differently. In addition to the way adolescents and adults talk about soap operas, they also attend to soap operas differently.

The findings in this study do not support a social learning theory account, according to which the content of television programming provides a basis for undesirable effects. This study has shown that soap operas provide both positive and negative depictions of sexual activity. This suggests that the age and/or background of the viewer has a more significant influence on what the viewer gets from the viewing experience. 
References

Alexander, A. (1985). “Adolescents' Soap Opera Viewing and Relational Perceptions." Journal of Broadcasting and Electronic Media 29(3), pp. 295-308.

Babrow, A. (1987). "Student Motives for Watching Soap Operas." Journal of Broadcasting and Electronic Media 31(3), pp. 309-321.

Bandura, A. (1994). Social Cognitive Theory of Mass Communication in Media Effects: Advances in Theory and Research. ed. Bryant, J \& Dolf Zillmann, New Jersey: Lawrence Erlbaum Associates.

Beck, K. \& Frankel, A. (1981). "A Conceptualization of Threat Communication and Protective Health Behavior." Social Psychology Quarterly 44(3), pp. 204-217.

Berger, C. R. \& Calabrese, R. J. (1975). "Some Explorations in Initial Interaction and Beyond: Toward a Developmental Theory of Interpersonal Communication." Human Communication Research 1(2), pp. 99-112.

Biracree, T. (1994). Soap Opera Mania: Love, Lust and Lies From Your Favorite Daytime Dramas. New York: Prentice Hall.

Brown, J., Dykers, C., Steele, J. \& White, A. (1994). "Teenage Room Culture: Where Media and Identities Intersect." Communication Research, 21(6), pp. 813-827.

Brown, J. \& Newcomer, S. (1991) “Television Viewing and Adolescents' Sexual Behavior." in Gay People, Sex and the Media. New York: Haworth Press. 
Brown, J. \& Walsh-Childers, K. (1994). Effects of Media on Personal and Public Health in Media Effects: Advances in Theory and Research. ed. Bryant, J \& Dolf Zillmann, New Jersey: Lawrence Erlbaum Associates.

Budd, R., Thorp, R. \& Donohew, L. (1967). Content Analysis of Communication. The Macmillan Company, New York.

Buerkel-Rothfuss \& Mayes, S. (1981). Soap Opera Viewing: The Cultivation Effect. Journal of Communication 31(3), pp. 108-115.

Butler, J. (1991). "I'm Not a Doctor, But I Play One on TV": Characters, Actors, and Acting in Television Soap Opera. Cinema Journal 30(4), pp. 75-91.

Cantor, M. \& Pingree, S. (1983). The Soap Opera. Beverly Hills: Sage.

Carney, T. (1972). Content Analysis: A Technique For Systematic Inference From Communication. University of Manitoba Press, Canada.

Courtright, J. \& Baran, S. (1980). "The Acquisition of Sexual Information by Young People." Journalism Quarterly 57, pp 107-114.

Faludi, S. (1991). Backlash: The Undeclared War Against American Women. New York: Crwon Publishers, Inc.

Fine, M. (1981) "Soap Opera Conversations: The Talk That Binds." Journal of Communication 31(3), pp. 97-107.

Frenier, M. D. (1992). "'Seventh and Eighth Graders 'Read' Daytime Soap Operas in Three West-Central Minnesota Public Schools" in Staying Tuned: 
Contemporary Soap Opera Crtitcism. ed. Frentz, S. Bowling Green: Bowling Green State University Popular Press.

Greenberg, B. S., Adelman R., and Neuendorf K. (1981). "Sex on the Soap Operas: Afternoon Delight." Journal of Communication 31(3), pp.83-89.

Greenberg, B. S. \& D’Alessio, D. (1985). “Quantity and Quality of Sex in the Soaps" Journal of Broadcasting \& Electronic Media 29(3), pp. 309-321.

Harris, R. J. (1994). The Impact of Sexually Explicit Media in Media Effects: Advances in Theory and Research. ed. Bryant, J \& Dolf Zillmann, New Jersey: Lawrence Erlbaum Associates.

Jo, E. \& Berkowitz, L. (1994) A Priming Effect Analysis of Media Influences: An Update in Media Effects: Advances in Theory and Research. ed. Bryant, J \& Dolf Zillmann, New Jersey: Lawrence Erlbaum Associates.

Kielwasser, A. \& Wolf, M. (1989) “The Appeal of Soap Opera: An analysis of Process and Quality in Dramatic Serial Gratifications." Journal of Popular Culture 23, Fall, pp. 111-121.

Krippendorff, K. (1980). Content Analysis: An Introduction to its Methodology. Beverly Hill: Sage.

Larson, S. G. (1991). "Television's Mixed Messages: Sexual Content on All My Children." Communication Quarterly 39(2), pp. 156-163.

Lemish, D. (1985). "Soap Opera Viewing in College: A Naturalistic Inquiry" Journal of Broadcasting \& Electronic Media 29(3), pp. 275-293. 
Liebert, R. \& Sprafkin, J. (1988). The Early Window: Effect of Televsion on Children and Youth. New York: Pergamon Press.

Livingstone, S. (1989). Interpretive Viewers and Structured Programs: The Implicit Representation of Soap Opera Characters. Communication Research 16(1), pp. 25-57.

Lowry, D. T., Love G., and Kirby M. (1981). "Sex on the Soap Operas:

Patterns of Intimacy." Journal of Communication 31(3), pp. 90-96.

Lowry, D. T., Towles D. E. (1989) "Soap Opera Portrayals of Sex, Contraception, and Sexually Transmitted Diseases." Journal of Communication 39(2), pp. 76-83.

Modleski, T. (1982). Loving With a Vengeance: Mass-produced Fantasies for Women. New York: Methuen.

Moores, S. (1993). Interpreting Audiences: The Ethnography of Media Consumption. Thousand Oaks, CA: Sage Publications.

Morgan, D. (1988). Focus Groups as Qualitative Research. Newbury Park, CA: Sage Publications.

Nielsen, A.C. Co. (1995). Nielsen System Ratings. Northbrook, Il.

Olson, B. (1994) "Sex and the Soaps: A Comparative Content Analysis of Health Issues." Journalism Quarterly 71(4), pp. 840-850. 
Peterson, J., Moore, K. \& Furstenberg, F. (1991). "Television Viewing and Early Initiation of Sexual Intercourse: Is there a link?" in Gay People, Sex, and the Media. New York: Haworth Press.

Perse, E. \& Rubin, A. (1989). "Attribution in Social and Parasocial

Relationships." Communication Research 16(1), pp. 59-77.

Rubin, A. \& Perse, E. (1987). “Audience Activity and Soap Opera

Involvement: A Uses and Effects Investigation." Human Communication Research 14 (2), pp. 246-268.

Signorielli, N. (1991). “Adolescents and Ambivalence Toward Marriage: A Cultivation Analysis." Youth and Society, 23(1), pp. 121-149

Silverman, L. T., Sprafkin J.N., and Rubinstein, E. A. (1979). "Physical Contact and Sexual Behavior on Prime-Time TV." Journal of Communication 29 (1), pp. 33-43.

Van Evra, J. (1990). Television and Child Development. New Jersey: Lawrence Erlbaum Associates. 
APPENDIX A

Contents

Page

$\begin{array}{ll}\text { Initial Survey } & 73\end{array}$

$\begin{array}{ll}\text { Primary Survey and Coding Instructions } & 74\end{array}$

$\begin{array}{ll}\text { Definitions } & 75\end{array}$

$\begin{array}{ll}\text { Coding Sheet } & 76\end{array}$ 
Name:

Age:

Of the soap operas listed below, mark the shows that have characters or plots that you recognize. You do not need to watch the show regularly.
( ) 1. Loving
( ) 3. One Life to Live
( ) 5. Young and the Restless
( ) 7. Guiding Light
( ) 9. Days of Our Lives
( ) 2. General Hospital
( ) 4. All My Children
( ) 6. As the World Turns
( ) 8. Another World
( ) 10. None of the above

Thank you for taking the time to answer this brief questionnaire. 
Age:

Participant \#

1. Which best describes your racial or ethnic identity?
( ) 1. White
( ) 3. Native American
( ) 2. African-American
( ) 5. Hispanic
( ) 4. Asian-American
( ) 6. Other

2. What is your educational level?

( ) 1. High School student

( ) 3. College student

( ) 5. Graduate student

( ) 2. High School graduate

( ) 4. College graduate

( ) 6. Professional degree

3. Approximately how many hours per week do you watch television?
( ) $1.0-10$
( ) $2 \cdot 11-25$
( ) $3.25+$

4. Approximately how many episodes of daytime soap operas do you watch per week?
( ) 1.0
( ) $3.6-15$
( ) $2.1-5$
( ) $4.16+$

5. If you do watch daytime soap operas, at what age did you start?

6. If you do watch daytime soap operas, which do you watch? (check all that apply)

( ) 1. Loving

( ) 3. One Life to Live

( ) 2. General Hospital

( ) 5. Young and the Restless ( ) 6. As the World Turns

( ) 7. Guiding Light ( ) 8. Another World

( ) 9. Days of Our Lives

This is a study of the sexual content of daytime soap operas. On the video tape provided is an episode of a daytime soap opera. You will need to view all of the episode, except the commericials.

Attached is a sheet to mark any sexual content that you may observe during your viewing. On this sheet are category headings for the different types of sexual activity. On the next page are definitions of each of these categories. When you observe one of the listed occurrences, indicate your observation by placing a mark in the box that describes the act. Place a mark in a box every time you observe a sexual activity. Mark the same occurrence twice if it is interrupted by a commercial and shown again after the break. Mark each verbal reference seperately, even if it happens in the same scene. 
Erotic touching: interpersonal touching that had clear sexual overtones, demonstrated or intended to demonstrate sexual love, or aroused or sexual desire.

Includes: 'heavy' kissing, sexually romantic embraces and hugs, sexual caressing or touching of any part of someone else's body, and other similar touching behaviors.

Excludes: casual hand-holding, an arm casually around someone's waist or shoulder, a casual 'peck' type of kiss, nonsexual greeting and farewell kisses, parent-child kissing and hugging (unless incest was implied), and other nonsexual touching."

Note: If there is any question in your mind if the touching is erotic enough, leave it out.

Heterosexual intercourse: verbal, implied, or physically depicted.

Verbal references to heterosexual intercourse: 'an affair,' 'cheat on me,' 'roll in the hay,' 'shack up with her,' 'unfaithful,' and 'make love.'

Implied heterosexual intercourse: when a scene depicts the start or end of lovemaking but did not show the physical act itself.

Commitment level: married, committed but not married or uncommitted. With your best guess, determine the commitment level of the couple involved in the sexual content. Commitment level can be determined by exclusiveness of the relationship, legal and living arrangements, and conversations about intentions and feelings. The category of uncommitted includes "one-night stands," prostitution and rape.

Safer Sex: talking about, implying or practicing any form of pregnancy prevention and/or sexually transmitted disease (STD) prevention. Also, verbal, implied or physical depiction of someone who has contracted gonorrhea, syphilis, herpes, AIDS, or other STDs.

Adolescents: sexual content involving adolescents, including erotic touching, verbal reference to sexual intercourse, implied sexual intercourse and references to safer sex. 
Title:

Date Aired

\begin{tabular}{|l|l|l|}
\hline \multicolumn{3}{|c|}{ Erotic Touching } \\
\hline Married & Committed/not married & Noncommitted \\
\hline & & \\
& & \\
\hline
\end{tabular}

\begin{tabular}{|l|l|l|l|l|l|}
\hline \multicolumn{5}{|c|}{ Heterosexual Intercourse } \\
\hline Married Verbal & Married Implied & Committed Verbal & Committed Implied & $\begin{array}{l}\text { Noncommited } \\
\text { Verbal }\end{array}$ & $\begin{array}{l}\text { Noncommitted } \\
\text { Implied }\end{array}$ \\
\hline & & & & & \\
& & & & & \\
\hline
\end{tabular}

\begin{tabular}{|l|l|l|}
\hline \multicolumn{2}{|c|}{ "Safe Sex" } \\
\hline Pregnancy Prevention & STD Prevention & STD Contracted \\
\hline & & \\
& & \\
\hline
\end{tabular}

\begin{tabular}{|l|l|l|l|l|l|l|l|l|l|}
\hline \multicolumn{8}{|c|}{ Adolescents } \\
\hline Erotic Touching & \multicolumn{2}{|l|}{ Intercourse Verbal } & \multicolumn{2}{|l|}{ Intercourse Implied } & Safe Sex \\
\hline Married & Comm & N Com & Married & Comm & N Com & Married & Comm & N Com & \\
& & & & & & & & & \\
& & & & & & & & & \\
\hline
\end{tabular}

\section{Comments:}


Appendix B

\section{Adolescent Focus Group Transcript}

J: Which soap operas do you watch?

E: All My Children and the end of General Hospital. That's all you really need to see of it to keep up with the storyline.

J: Which do you watch?

S: Days

T: Days

J: I watch a little bit of both of those and I haven't seen either of them in quite a while, so first what is happening on Days.

S: Vivianne was trying to get Victor to marry her and if he wouldn't marry her she would take custody of her son Philip or something like that.

T: I hardly watch Days anymore because of tennis and stuff, but the previews, I mean you just get a glance, two seconds of it you know exactly what's going on. And that whole storyline lasts for like a month and never dies off.

S: Three months more likely with Kari and Austin's story.

It never dies off you know exactly, you know what's going on. I don't even have to watch it.

J: Lynn came back to town? 
S: Ya she wants money from Sami and Lucas so she won't tell about Austin, I mean what she did to Austin.

E: Laurel should be here she gets, she watches that one everyday.

SS: She tapes it if she can't. Like Ryan's dad too. We should have him here. He tapes them everyday

S: Which one?

SS: Um Days

All: Really?

S: How funny.

SS: He talks about it in psychology. Ya he tapes it and watches every night.

J: Do you watch All My Children frequently?

E: Ya, almost everyday. If I can't get home from school I figure, oh well I'll catch up tomorrow. You don't miss a lot when you miss it.

$\mathrm{J}$ : What's going on on All My Children?

E: Um Tad and Dixie just broke up. Because Tad cheated on her, once again. He has like all 20 million years this soap has been on. With Liza who came back to town. And they were like together a long, long, long time ago before I was born, I don't know. My mom has watched this like forever too, so if is like there's someone I don't know she tells me about them. Um, so they broke up. There's this Doctor Kinder who is like dealing drugs to Erika Kane. And he has this secret mystery woman he like keeps in the cellar. And he's I don't know. Just the other day we heard her name, he 
keeps her hidden, like we don't ever get to see her. He's trying to get her information out of her ER doctor, where is it ? You don't really get to know what's going on there. Um, what else. Erika just came back from Betty Ford. She got off drugs and is all fine now. But, her marriage is having problems and (unintelligible).

J: What ever happened to Haley and Alec?

E: Oh, He was swindling her money. And he is now like on the Bold and the Beautiful or something. I don't know. He got killed off or down or in jail. I don't know, something like that. I'm not sure what happened to him because I missed a lot of it this summer. Um, I don't know, ya he was taking her, oh and he was having an affair with Haley's mother. So she's gone now. She [Haley] is with Matao now, Matao Santos. And his sister Maria and Edmund, Edmund is a Marrick so is Dametri. Maria and Edmund, um they have a baby, they adopted a baby. And the mother is like sixteen, she's like our age and she is in love with Edmund. And so like they are worried that she is going to take the baby back. But the baby was just really sick recently. And um this baby is just having problems. First they couldn't have a baby and then (unintelligible) so they couldn't have a baby so they adopted a baby an then the mothers going to take it back and all this stuff. I don't know theirs a million other characters on there. Janet, she was like two years ago she killed Dixie's brother, went to jail and had cosmetic surgery and came back and she was Jane Cox but she blew that whole cover and like nobody in town likes her. Anyways like two years ago she pretended to be her sister Natalie, she killed off her sister Natalie and all this. And 
then I don't know that happened so she was disguised as Natalie. And then she had cosmetic experimental surgery and she as Jane Cox. And then that whole thing got, I don't know, uncovered. And then now she's trying to become Brooke English. And she is trying to find all this stuff out about her and um she is going to have plastic surgery again. And try and make her look like Brooke and kill off Brooke because Brooke is now dating her ex-boyfriend that she wants and was like the only love of her life, and all this stuff.

S: OK (everyone laughs)

J: Why do you choose Days over any other soap opera?

S: I don't know

T: You just like you just watch it. You get use to it cause you just want to know the conclusion, that's why.

SS: I think to for a lot of kids in school, it's when they get out of school.

E: Actually they are both on at the same time.

S: It is a choice between the two.

E: I just watch All My Children that's when my mom use to have the afternoons off. Go to work early and get off earlier. And so it would always be on when I got home. So its like been on at 3:00 everyday since I've known.

T: My mom use to have me record Days for when she gets home from work she doesn't get home until like whatever. 
S: We even watch part of Another World. Like, What's going on here. It's just what's on.

T: Ya cause usually when you were little you watched cartoons.

E: Hey we still watch cartoons sometimes.

T: Ya but I don't know when you get older there is nothing ... either you do you homework or if you don't have any activities after school you sit and watch the tube all day...

S: Sit and watch the soaps, sit and listen to music.

T: So you flip through the channels and you find something interesting.

S: You find your show.

$\mathrm{J}$ : And then once your hooked into the story.

T: You do what ever it takes to watch it.

E: Ya like what she said you always want to know the conclusion. There's never a conclusion. There is always something going on.

S: Ya its like you, oh it's actually gonna happen, and then it doesn't.

E: Ya and then it goes to another week.

S: Ya it's been what, seven months now and I'm still watching Days trying to figure out what's gonna happen between Kari and Austin.

$\mathrm{J}$ : Is the Austin and Kari storyline the one you like the best.

S: Ya cause I really want them to get together. And Sami's getting on my nerves. Her character is really bugging me. 
$\mathrm{J}$ : What is your favorite storyline on All My Children?

E: Um, ask her, I need to think about that one.

T: Ya but probably the one I would watch is Bo and Hope. Just cause I like, you know, their couple.

S: True love.

T: I just like how they just you know, she dies, she comes back, he dies off, he goes somewhere. He finds three wives in the mean while before she comes back.

S: Two, isn't it

T: Two, what ever and then they still get together. I don't know.

S: Ya she goes and gets buried in the snow a couple weeks months later he finds her.

T: She is still alive, buried alive. So, I don't know I just like the two of 'em just romantic. I don't know, I just like them. They're together all the time.

E: O.K. probably Janet Green cause that's the storyline that I've like known from like the very beginning, since they've started that one. It's always just neat to see how she works around things. And how you just sit and say "come on people, figure it out." You know, the other characters. Probably the most corny but the most interesting I guess.

S: Aren't Noah and Julia on there.

E: Oh ya they just got back from Jamaica cause he was like on the run. As a felon. S: Why. 
E: Cause they say he kill (unintelligible) and her baby. And Taylor is a cop and she hid the gun so they didn't have a gun, and then she used it against him.

S: Cause she wanted Noah, didn't she.

E: Ya

S: Like did he find out she wasn't really pregnant with his child.

E: $\mathrm{mm} \mathrm{hmm} \mathrm{They} \mathrm{went} \mathrm{to} \mathrm{Jamaica.} \mathrm{They} \mathrm{like} \mathrm{got} \mathrm{on} \mathrm{some} \mathrm{boat} \mathrm{and} \mathrm{they} \mathrm{ended} \mathrm{up} \mathrm{in}$ Jamaica. And um ya that storyline just kind of ended. I don't know, they met this lady friend who did all this spiritual herb and stuff, you know and she made this potion that they like drank.

S: To tell the truth?

E: huh?

S: It made them tell the truth

E: No it like slowed their heart-rate and their breathing so they'd be pronounced clinically dead. So once they told everybody they died. That's when they sort of called off the search and everything and she brought them back to life and they went back and made Taylor tell the truth and its fine now.

S: So Taylor told the truth.

E: Ya he got her to like, they were all back in Pine Valley, they got shipped back. They had to be shipped back in coffins so everybody would think they were dead. S: That's not cool. 
E: I don't understand how they keep going. Ya they like, I don't know, went to her apartment one night and like Noah appeared like as his ghost or what ever.

S: His spirit.

E: Ya cornered her and made her tell the truth, and she did, and they arrested her and the conviction got over-turned.

S: That was a good idea.

$\mathrm{J}$ : Now time for a new storyline.

S: I bet she gets bust out of jail.

E: Ya now he asked her to marry him for the third time cause each time they tried to get married something happens.

S: Maybe it's time they take the idea that they aren't suppose to be together.

$\mathrm{J}$ : When you watch do you usually watch alone?

E: I'm the only one home when I watch. Unless my mom comes home then we watch it together. She always asks me like, we'll be at dinner one night and she'll ask me like what's going on with so and so. And we'll be talking and my dad goes who are you talking about. And then he like makes fun of us and be like so and so's sister is dating her brother-in-law's ex-husband and on and she's pregnant and all. He thinks its so funny that we like talk about it in conversation.

J: How about you guys?

T: We watch together. And my mom sometimes watches if she's not cooking or what ever. My sister, that's about it. 
S: The girls.

$\mathrm{T}$ : The four girls.

S: Then we fight for the TV.

T: Ya we like watch the same channel up and down the, where ever, one upstairs, one downstairs, one in the other room and its all the same channel, my brother gets so frustrated. "I want to watch my cartoon." and everybody has, I'm upstairs watching TV, they're down stairs, there's one in the kitchen you know, all the same channel.

S: It's pretty weird.

J: Do you have friends at school that you talk to about soap operas

S: That's what I always do. First, period this morning we were like having a discussion about Sami and Austin and Kari and like what's going on now and everyone was going "Sami must die" and how much we hate her character and we were talking about what's going on with Marlena and John. And everybody. $\mathrm{J}$ : What is going Marlena and John.

T: John has like strong feelings for Marlena.

S: Ya he really likes Marlena. Marlena never like expresses her feelings back. And like Kristin is like pregnant now. And John like wants to be responsible for it, his child, you know, and Marlena doesn't want Kristen to get hurt. And Kristen knows that John doesn't like her cause she found the letter that, you know.

T: He was under hypnosis while he told. 
S: No she gave him this drug and Laura asked if knew about his past. I think he did confess and Kristen overheard everything so she set the alarm off. So people would go. Cause she didn't want them to find out that he really liked Marlena. Now she's trying to kill Marlena.

T: Ya, I heard that.

S: Then she drugged her mom, only she doesn't know it's her mom. Cause she heard her.

$\mathrm{T}$ : That lady in white, chick?

S: Ya it's her mom.

J: Is Kristen's mom?

S: She supposedly died in a fire cause Stephano set the house on fire or something like that and she came and Kristen didn't know at first, John knows who she is and Peter didn't believe and Kristen sort of believed and Peter convinced her. So she put some kind of medicine to make her go crazy so she won't talk. And Peter like he knew, like Abby got a little music box and then Peter like overheard the lady singing it. When he was little his mom sang it, so he figured out that it was his mom and so he turns the plane back to go back to Salem, cause they were on their way somewhere on their honeymoon. With Jennifer you know.

J: What did Peter do to make Jack hate him?

S: Peter is a, he deals drugs, he's really rich and he has people working for him everywhere. 
T: I though Jennifer knows about it

S. No Jennifer, OK you know how the lady in white knows that Jude and Peter had something going on.

$\mathrm{T}: \mathrm{Ya}$

S: And then but see that's her son. So she doesn't want Peter get in trouble. So she denied that she saw it. So remember that Jennifer was yelling at Jack because she knows that Jack really wants her back.

T: Jack must be in love.

S: Peter's always like "give up Jack." You know you just really want her back blah blah blah. And they get into this big ol' fight. I don't know, so the storyline now is like Kristen is trying to kill Marlena.

J: Did Marlena ever get up the nerve to tell

S: No, cause she doesn't want to hurt Kristen. And Kristen on the other hand doesn't care. And she's like, I don't know, if I was her I would not go killing if the man you really like does not like you, it does not work out that way.

$\mathrm{J}$ : Who is your favorite character that you can relate to the best. First who do you relate to the best.

S: I don't relate to any.

J: You don't feel like you relate?

S: No because their just, not like, it's not really real they way it's so off the wall. You could never be like them. 
$\mathrm{T}$ : I'm trying to think of the young characters.

S: Ya I mean somebody that's.

T: Sami no.

S: She's totally.

T: Most are old well older not old.

S: Maybe Jamie, she's the only one, she more of a, I mean she doesn't do any of those things. She is always on Sami's side. She is always there for her friends and stuff. But she is trying to get Kari and Austin together. She tries to help out but she doesn't want to hurt Sami for what she did. She drugged Austin so he'd sleep with her.

$\mathrm{J}$ : Can either of you think of anybody.

E: Not that I relate to but I like Dixie Martin, Dixie Cooney Martin but

S: She's been married that much?

E: She's like um ya well like Erika Kane's been married like ten times.

S: How come?

E: Just because.

S: What do they do kill every man she like marries?

E: Oh no, divorce all sorts of things, mostly divorce. But I like her[Dixie] because she is one of the most reasonable decent people. And I like Brooke English they're like more reasonable.

S: Normal 
E: Ya ya if you compare them they're more of an actual person than any of the other characters. They're just nice little ladies that are at home and make lunch for their kids sort of, I don't know. So ya, either one of them.

T: I would probably go for Hope.

S: I knew you were going to say that.

T: Because I like her character so much.

S: She's a sweety though, she is.

T: And just the way she never gives up on trying anything. You know.

E: Like with Bo, she never gave up on Bo.

T: Ya and what ever, she's a cop and doesn't give up on her cases and like

S: Even though Bo wants her to.

$\mathrm{T}$ : If she gets in trouble or what ever she always covers up or she knows how to what ever. She's not devious. You know she's

S: She's very, she's kind of real life, I guess.

J: So who do you hate the most

S: Sami

$\mathrm{T}$ : Kristen

S: I know, her and Sami are like alike

T: Don't like her never did like her 
S: I wonder if she's a drag queen. We were talking about this yesterday. She looks like a guy. We were talking about it in class and the guy behind us was looking at us like we were weird.

SS: I recognize some of the names by people talking about it at school.

E: Who do I hate? Taylor or who is the other one though. She is just so mean spirited. There are some characters that it is not hard to dislike.

T: Erika Kane, is she like an evil person too.

E: Um when she wants to be, but from her twelve step program she has learned to be nice now apparently I don't know so she's suppose to be a better person now.

S: Suppose to be

E: She is now writing a book about her drug addiction so

SS: How old is she on the show?

E: They make her look young but she's older in real life. She has a daughter on the show that's about twelve or thirteen. She lives in Seattle.

J: So how realistic do you think soap operas are?

S: Not at all realistic, it's just I mean there are some parts that you can relate to but you know, drugging people, you know, getting them into bed having their kid and stuff that's not what people really do.

E: Framing them with the police, potions that make you seem dead

T: Coming back after twenty years saying you were lost in some county in the Middle East or something captured in some strange prison. 
S: Buried in snow for like five days and still be alive.

E: Anything can happen though so this could all happen but, ya right, and not like all in one little town. Ya it's all very unrealistic.

S: Ya it happens in Another World, As the World Turns I use to watch One Life to Live it was kind of good but I got lost some how.

E: You know the dumbest one? It use to be Loving and now it's The City. The show was getting such bad ratings that they killed off all their characters. Like almost all the characters and anybody that was left moved to the city and now Morgan Fairchild is on it.

$\mathrm{J}$ : They killed everybody off?

E: I don't know who was doing all the killing but like almost everybody in the town died. So they totally restructure the show and everybody lives in the city. And there's all these new characters now and it sucks even more.

J: What about it sucks?

E: It's so unrealistic and corny.

$\mathrm{T}$ : They haven't established a storyline yet.

E: Ya there's nothing really, there's nothing that peaks your interest.

S: Soap operas have the same things going, like the pregnancy thing with Taylor and there was like SamI. Well she didn't fake her pregnancy but they have the same ideas and stuff. And there was that one for Another World some guy came back. He had 
amnesia or something he came back. Hope had amnesia she came, she finally remembered who she was.

E: Tad Martin did that too on All My Children. Cause he was living in California and ended up coming to Pine Valley and had a twin and,

J: What ever happened with Taylor's pregnancy.

S: She's not really pregnant she just said she was to keep Noah around

E: Cause Noah is in love with Julia and always will be and all this stuff and will never love Taylor but she tried to get someone to work with so they could still a baby. But they found out she had two hysterical pregnancies. That is when you imagine you have a baby and all this. And so,and they, Julia who's with Noah, her sister Maria Santos was a doctor and so she called up Taylor's records which she shouldn't have done and it was like illegal but they called up her records anyway and it said that she was never really pregnant that both tests were false. They tried to get the doctor, her doctor to testify in the court trials to say she is just weird and crazy and she is she is just really insane. And um the doctor wouldn't testify.

S: Isn't she really rich, her mom

E: But her mom like cut her off cut off her money supply and everything because she knew she was doing weird stuff. It was her mom who eventually kind of made her tell the truth.

S: But her mom wanted her to like get together with Noah 
E: Well right, but then when she found out she found out that Noah was like really decent and that her daughter was actually insane, and so she was like on Noah's side. She tried to get her help. "Oh let's take a trip to Europe."

S: They're always going somewhere.

J: When you said that Noah would only love Julia, you said it real sarcastic do you not have faith.

E: Well no, not, no because well I mean because well who on that show has been, never cheat on each other, live together for a while, the oldest couple the Martins. Um Joe and Ruth Martin. And that's like I mean, well when you, society today I mean the divorce rate is like over $50 \%$ and um, soap operas just exist that way that's what it is relationships starting and ending and people cheating on each other.

S: If that didn't happen it's not really relationships

E: Ya I mean it's good because you always think theirs two and you want them to stay together and be happy but that's just not how it's going to be something else will happen at their third wedding. So, like she said it's not meant to happen. Everybody on that show has been married to each other.

SS: I'm surprised there hasn't been incest.

T: Didn't something like that on Days where they find out, no I mean Young and the Restless and she finds out there's a girl and guy and she fell in love with this guy and they had been seeing each other for a couple months and then they realize they are brother and sister. 
E: Day to day you can always tell what is going to happen but like the ones on Friday you know, oh here it goes for another week.

S: I think there should be a show that sums up what has been happening.

E: You can read it in TV Guide too they have those things I always read that too

T: Or you call Inside Line.

S: They also have it on the internet they have live conversations about it.

T: They have that thing "Hey all you Days fans who can't wait to hear, call this number to hear what will happen," and stuff.

E: Well you kind of know what's going to happen. I wonder what they say they aren't going to tell you the storyline.

S: They probably just get you more hooked. That's their job.

E: What a way to make money

S: We could drop out of school and be rich.

SS: What did (unintelligible) get on his SAT?

E: 1460 , one girl got a perfect score.

S: She was Chinese

E: See nothing like that is ever on soap operas. Ya, "what did you get on you SAT's"

S: It's not about high school it's about love.

E: No one goes to school.

T: They're too old

E: Well there's Laura on All My Children. 
T: Ya what about Sami how old is she

S: She's like sixteen. She never goes to school what does she do, just sit there?

E: Actually there was a storyline about high school just recently. On All My Children just recently Michael DeLaney, he was Laurel's brother and he came back to town and all this and he was a history teacher at the High School and um like the best teacher in the school all the kids loved him. Great teacher, everyone was learning so much and grades were up and then they found out he was gay and the parents went irate and the school board fired had him kicked out and everything.

S: Because he's gay?

E: Ya and the kids protested

S: That's dumb

E: And had all these riots outside bring Mr. DeLaney back. Ya, the kids wanted him there he was a good teacher and they don't care so it was like you know one of those generation gap things. And one of the girls, the youngest Santos, her parents made her go to Catholic school and she can't see her boyfriend. I don't know but Mr. DeLaney is back teaching. But they were on the talk show The Cutting Edge and um him and his sister Laurel, and this um gay basher guy that worked at the station he pulled out a gun and went to shoot Michael and he missed and killed Laurel. And they blamed Janet of it and she didn't really do it.

S: Why did he want to shoot him?

E: Because he was gay. 
S: oh God

E: Is like Melrose and all that considered soap opera?

J: ya they're night time soaps.

S: I use to watch like Melrose and 90210 , I use to love 90210

SS: Ya, me too, Melrose Place is, no.

T: I don't like Melrose Place anymore.

SS: They like switch boyfriends, like every show.

T: But they're weak now.

S: Every night or something, you know 90210 I mean I use to like it when like

Brenda, Luke Perry were seeing each other, until he had like a fling with Kelly and everything just went downhill.

SS: And then I didn't like what's her name, blonde, set fire, went crazy.

T: Emily

SS: Ya oh I hated her.

E: Ther're together in real life too.

SS: I know, I still can't believe it, I hate her, I still not even in ER I don't like her.

S: And then after like Dillon and Kelly were dating her, then Brendon started seeing her, and before that Steve was seeing her.

SS: I know

S: They were all seeing each other

SS: Steve always liked her though, Steve wanted her. 
S: She like basically went around.

E: Didn't they like graduate our Freshman year.

SS: No, no they graduated, cause they were like seniors twice

S: It was last year.

E: Oh were they?

SS: They didn't know what they were gonna do with them yet.

S: They graduated last year or something like that.

SS: The year before.

E: It seems like they've been in college for a while.

SS: That's a cool show.

S: That's a good one.

$\mathrm{T}$ : I guess that stuff is realistic.

SS: ya that one is like diet pills and mom's on drugs

E: Ya they deal with more issues.

T: Kelly just got off drugs.

SS: She did?

S: Because her ex-boyfriend got her hooked on them.

E: Hey you still watch it.

$\mathrm{T}$ : I saw the preview, all I needed to see was the preview

SS: The painter? The painter guy got her hooked.

T: Wasn't it Cocaine or something like that. 
SS: Oh my gosh.

S: She had this little bottle and she wacked him, my little brother watches it. My eleven year old brother is sitting ther watching.

SS: What's happening with Jane?

S: Oh her and um what's his name, and Jake are seeing each other.

E: Who's Jane.

SS: Before, she was married to Michael.

S: And then Sydney and got married to Kimberly.

SS: No he never married Sydney.

T: Ya he did.

S: He married Kimberly then Sydney and then he came back.

SS: Cause Kimberly died.

S: And then she came back.

SS: Then she came back with the scar that was so horrible.

T: She took it off.

$\mathrm{J}$ : Which show is this?

SS: Melrose Place.

S: They brought Melrose Place on because of how Jake and Kelly went out.

E: That's how they intoduced it.

SS: They were like, let's see where Jake lives. 
S: And then like they broke them off because like she was too young or something like that. Cause they went to a bar and she goes "what do you want a chocolate milk." SS: I don't remember that.

S: Cause that was like the first episode or something like that.

SS: I still want Billy and Allison to get together.

T: Allison gets on my nerves.

E: My mom says Billy's a bad guy now.

S: No he can't be.

T: Ya Billy's a bad guy.

E: She says cause he's like got on a professional soccer team now and maybe they are going to kill him off.

T: They're going to kill him off.

S: Cause they said one of the characters is going to be killed.

SS: Oh ya they're dead because it happened last week.

E: It's probably him then.

SS: Cause it happened last week so, I remember I saw the preview and I wanted to watch it but I wasn't home.

S: I heard her and Jake were seeing each other in real life.

SS: Also is Sydney and, no Sydney and Jake were together.

T: They were together and they were seeing each other in real life and now he's seeing Jane. 
SS: What ever happened to Michael and Kimberly.

S: They broke it off I think, she's like psycho

E: She always was.

S: But she's still a doctor after what she did and everything, she's still a doctor.

E: What did she do.

SS: What about, oh ya and hit a friend Matt, so I like saw one thing where he

T: He's still on the show isn't he

E: He's gay

T: Isn't he out though

SS: I saw one episode where he came out and then he went back into the closet I guess.

T: Then there was that Models Inc. one that sucked.

S: Did you watch that.

E: No

SS: A long time ago, I like that one character that came from the country

S: Oh Brigetta.

SS: Jeez you know this stuff.

S: I watch all these thing.

J: If you don't watch them you find out about them.

S: Cause you friend's sitting there saying did you see what happened.

SS: Oh my god I can't believe it. 
S: Eventually you'll find out anyway, I mean if you see a little preview of it you just know what's going to happen.

SS: Ya the previews you can just figure it out a lot of times. 


\section{Appendix C}

\section{Adult Focus Group Transcript}

\section{J: OK What's going on?}

JE: She looks at me. OK

JO: I gotta find out about today. K hasn't seen it for like a week so we totally have to bring her up to speed.

JE: Lynn is back and Lynn is totally blackmailing Sami and Lucus for money. That's totally what's happening right now. She had been in Chicago

$\mathrm{K}$ : Who's that

JE: She's the nurse, the black nurse who use to date Jonah. And she knows about the drug that Sami gave Austin. And she said that "I will do anything to work for you." JO: Yes that one.

JE: Mrs. Roberts. Well they gave her ten grand and they told he they'd give her more in July when Lucus got his trust fund. But that wasn't enough for her, she spent it in like one day so now she's totally trying to get close to Kate, so she can totally sell the information to Kate. Cause she found out that Kate totally wanted to know.

JO: The long and short of it is that Kristen is totally showing her DiMira side. She is totally like hitting pictures of John and Marlena together stomping on the pictures. "I'm going to get him." She says stuff like "I will do anything to destroy you if you interfere with my happiness" 
$\mathrm{K}$ : Who did she say that to?

R: Herself

JO: Herself, but about Marlena and she's pregnant with John's baby.

JE: But the woman in white saw Kristen freaking out and of course she's really Kristen's mom so she's like I totally "have to help you." But Kristen thinks the woman in white is going to tell all her secrets to Marlena so Kristen stole the drug from Laura's purse that they gave John so he would have a memory and put it in the woman in white's milk so the woman in white would have side effects from this new drug that's suppose to make her have memories, which is totally frickn' lame because there is no drug on the planet that does that so anyway she stole that and gave it to the woman in white thinking that the woman in white would have side effects and everyone would think she was insane and they'd put her away in an institution but she doesn't know that she is doing that to her own mom

JO: But Peter figured it out today there was some little music box.

JA: They are on a plane where are they going?

JO: On their honeymoon

$\mathrm{K}$ : It's like a four month long thing

JE: And Abby had a music a box and it's playing Greensleves

K: So how does Jack feel about that

JA: Cause that's the song she was singing

JE: Exactly, and he's like we have to go back Jen cause I know who she is 
K: Well how does Jack feel about this little trip thing

JE: Oh he freaked and was like really depressed today and stuff

JO: Laura is totally stoked.

JE: ya Laura's like "maybe now you'll move on."

JO: Laura she's like she talks like this she's like "oh now I can have him."

$\mathrm{K}$ : And Marlena.

JE: She was so breathy yesterday.

JA: Oh I know I watched it.

JO: What was up with that.

R: "Oh Laura I asked you not to do that."

$\mathrm{K}$ : What about Jack and Jen

JO: OK Jack and Jen, Jen is totally into Peter she's like "I'm going to be loyal to Peter he's my husband Jack leave me alone." And Jack is on the same old Jack for the last three years. "I prove it. I'll prove."

JE: "I don't want Abby and you around him, what more proof do you need."

JO: Ya

$\mathrm{K}$ : And what about Kari and Austin

JE: They are totally screwed. Sami $I$ hate her guts.

JO: Oh I know

R: Oh I hate her

JE: Today she got money out of Marlena. 
R: Yes

JO: She's fatter than ever and she has huge, what's with her cleavage today?

R: Oh my God.

JA: Her clothes are so nasty.

JO: It was like four inches today, no it is like this and

$\mathrm{K}$ : And how old is she

JA: Is it worse than that gray dress she was wearing the other night.

JO: oh yes

$\mathrm{R}:$ ya

JE: That was so heinous.

JO: They are like sitting on this shelf and that I Dream of Jeanie ponytail. what was up with that. Her and Austin are kissing and they're pretty much on the path to starting a relationship.

$\mathrm{K}:$ ooh

JA: They are so disgusting

$\mathrm{JO}$ : It is like so wrong

$\mathrm{K}$ : Who starts it, they kiss?

JO: They both start it, they both start it, they both start it

JA: Who they both start what?

JO: They both start like they both initiate like the sex

JE: but it's more Austin 
R: Who

K: Austin's kissing her

JO: Oh ya totally.

JE: Full on because he thinks there's no chance for him and Kari.

K: So he's settling for her

JE: Ya because she is the "mother of his child."

JA: But is it?

JE: Oh it's totally Lucas's baby.

JO: What really bugs me with this show, I think I told you the other day that was that its got like the woman in white dragged a little but the fact that Peter today, I mean today he realized that he I mean that that's his mom I mean he could be on his honeymoon for like a week and then realized it. I mean that's pretty quick

JE: YA

JO: But this Sami and Austin thing has been going on for way to long and this baby being Austin's has gone on for way to long.

JE: $\mathrm{mm} \mathrm{hmm} \mathrm{I} \mathrm{think} \mathrm{the} \mathrm{reason} \mathrm{they} \mathrm{are} \mathrm{moving} \mathrm{the} \mathrm{woman} \mathrm{in} \mathrm{white} \mathrm{thing} \mathrm{along} \mathrm{is}$ because they're gearing up to bring Stephano back and they're trying to make another bad person. Victor's all good now, the whole Vivianne plot is old and tired and they have to get a new villain.

JA: Is Victor going to survive?

JO: ya 
JE: oh ya

JO: The next thing that is going to happen is Bo and Hope are like pretty much together

JE: I'm sorry Billie's coming back.

R: Billie's coming back?

JO: And now they're starting this little bickering back and forth and he's really upset that she is not being a mom to Sean

JA: He doesn't want her to get hurt.

$\mathrm{K}$ : He doesn't want her to be a cop any more and she's like "I want to be a cop I want to be a detective I'm doing the best I can."

JE: And they never work it out they always just like leave.

JO: So what's going to happen is that it is going to get progressively worse. Like the other day they had a pretty big fight yesterday like that was like you know.

$\mathrm{K}$ : It was like he was walking out.

JO: He was really angry cause I think they're gearing it up cause Billie is coming back on the show so they're gearing it up for them be like fighting when Billie comes back.

$\mathrm{K}$ : And Billie has to come back to support Kate.

JO: Oh totally, totally is coming back I know for a fact.

$\mathrm{J}$ : Who is Billie?

JO: She is Austin's sister.

J: She's was married to Bo. 
JO: Ya

$\mathrm{K}$ : No, did they get married?

JE: Well they had their little like marriage ceremony to themselves. But they never actually went through with the marriage because the desicrater dropped the big what ever you call it down on the ground in the church remember it burned down the church. Marlena was possess by the devil and all that shit and it was all.

JA: That thing went on forever.

$\mathrm{K}$ : Kari and Austin need to get over it.

R: I thought it was almost gonna happen when they were doing that photo shoot.

JA: When Bo and Hope were originally getting together they were the super couple and it took it took a year and a half for them to finally get together. They'd get together something would come between them, they'd get together something would come in between them. It was always something so.

$\mathrm{K}$ : It was the same thing with Kayla, I was just going to say Kayla and Steve and Shane

JE: It was the same thing with Kayla, he's gay in real life

$\mathrm{K}$ : In real life?

$\mathrm{R}$ : who is?

JE: Shane

$\mathrm{R}: \mathrm{He}$ is not.

JE: Yes he is. 
R: No he's not.

$\mathrm{JE}: \mathrm{He}$ is?

$\mathrm{J}$ : Who is he?

JE: He plays on the Nanny, he use to play Shane who was just like a rich European guy.

$\mathrm{K}$ : He's an ISA agent

JE: That's right

R: God, how weird, and Peach

JE: The maid lady.

R: Peachie, and now that's Kristen's house.

JO: Ya pretty much.

JE: Same set just the other direction. It has the secret wall and all that crap and now they're gearing up and they're gearing up Lexie big time, Lexie's gonna get pregnant.

$\mathrm{K}$ : What's going on with Lexie and stuff.

JO: Lexie is Stephano's daughter.

\section{JA: And Celeste?}

JE: And Stephano is doin' this secret stuff behind her to try to win her favor but she doesn't know about it yet.

JO: And Jonah is also Stephano's son

JE: no

$\mathrm{JA}:$ no 
JO: I thought so.

JE: Jonah is Abe's brother.

JO: I know but, but what about that guy when he was talking on the phone and he goes "anything for your boy boss."

JE: Well ya he wanted Jonah to get reinstated to medical school to make Lexie happy. That's why.

$\mathrm{K}$ : Why would Jonah make Lexie happy still?

JE: Because they're totally close they're all well that's the Carver family basically.

The parents are dead and there's the child ya

R: Boy she cared all right, God.

$\mathrm{K}:$ So are Lexie and Abe better?

$\mathrm{JE}: \mathrm{mm}$ hmm

JO: Ya they're totally together

JE: And they're talking about having a baby

JO: Except actually that's kind of a lie because of every time Lexie walks into Abe, like any other, like a talking situation, he's totally talking about Stephano like a snake or what total evil he is.

JE: $\mathrm{mm}$ hmm they're gearing up

JO: And they always show her like all aghast.

JA: "That's my dad." 
JO: They're talking about her father. She always says you know "why do you have to talk about him like that, he's my blood you know and that's me that you're talking about." And he's like "you're different your, not a DiMira."

$\mathrm{JE}$ : But she is.

JO: So you know, low and behold in about six months she'll start doing something like Kristen is.

JE: Oh I'm sure and it will split them up.

$\mathrm{K}$ : What else is happening with Kristen and them.

JO: Well I think they're going to get really being close to having that baby but she'll probably loose it.

$\mathrm{K}$ : Do you think she's going to have it?

JA: No, I think she's going to lose it, but she'll keep pretending JO: That's what I though if John has that damn baby he will have three kids with three wives.

JA: No Roman doesn't count.

JA: Roman does too.

JO: Who cares. cause John right now is like a total slut.

JA: Victor has three kids from three separate wives.

JO: who?

JA: Bo, who is Isabella's dad, Victor. 
JE: Isabella's mom was Piscano, and Bo is Caroline's and Philip's is Kate's. Victor's got kids from three different wives.

K: Who's Philip

JO: Remember the baby Vivianne carried for nine months

$\mathrm{K}$ : So Victor's in the hospital?

JE: $m m$ hmm,

$\mathrm{K}:$ He had a stroke

JE: He had stroke

JE: no

JO: He's totally under

JE: He's on life support. "Mike get in here quick his blood pressures going up."

JA: And then Kate went to Brussels and got a specialist

JE: They have got to get somebody on the show for Mike. Mike has like been alone for way too long.

$\mathrm{K}$ : What's going on with Vivianne and Kate?

JO: They were fighting.

JE: Oh my God they had the killerest fight scene in the hospital.

K: Who did?

JE: They beat the crap out of each other.

R: who?

JE: Kate and Vivianne. 
R: Oh I missed it.

$\mathrm{JE}$ : Kate had this short dress on and they were rolling around on the floor and her butt was all up in the air and they were scratchin' and stuff at each other. And they were totally trying to peel them apart

$\mathrm{K}$ : Does Kate know that Vivianne was trying to get the baby?

JA: Ya she knows everything.

JE: Ya she knows everything.

JA: The only thing she doesn't know for sure is that Vivianne implanted the baby on purpose.

JE: But she suspects.

JA: But she suspects, but she doesn't have any proof or anything but

JE: Vivianne's a bitch.

JA: Oh I hate her, she does add a little spice you have to admit.

$\mathrm{K}:$ Ya she does.

JO: Who, Vivianne, oh I love Vivianne she's my favorite cause she's so ridiculous.

JE: I totally like this Kate better than the other one.

$\mathrm{K}$ : Is that the same Kate?

JE: No it's not, you can tell by her accent

$\mathrm{K}$ : I thought it was the same one

JE: And her nose.

JO: Who? 
JE: Kate.

JO: That's a totally different Kate. I do not like the new Jennifer

R: I do not like the new Jennifer.

JE: She cannot act

JO: She bugs the crap out of me.

JE: Totally want John and Marlena to get back together and that would totally gear 'em up to bring Roman back.

R: Oh my god

JE: Oh but have you noticed like every time they show Alice not she's sitting down, I think she's getting old.

JO: She is getting totally old.

JE: It's like Tom, when Tom was getting sicker and sicker they would only show him sitting down and lately they've only been showing Alice sitting down.

JO: I read in a magazine that they might be bringing back, we were talking about this today, Sami's twin brother.

JA: Eric

JE: He totally needs to come back.

JO: They're going to bring Eric now the character is going to graduate college soon.

JA: But Sami's like seventeen.

JO: But he's going to come back.

JA: And he's graduating college. 
K: No no Sami just graduated high school.

JO: They went away to boarding school.

JE: I want them to get somebody together with Mike. There's nobody on the show to get together with Mike.

$\mathrm{K}$ : Maybe that new girl Lynn will.

JE: But they need to get John and Marlena together.

JO: No they won't have a mixed relationship.

JE: Are you talking about John and Marlena?

JO: We're talking about Lynn and Mike.

JE: Oh no they would never do that.

JO: I don't think they would, do you think.

JA: I don't know.

JE: No they're not gutsy enough, they haven't even really done the whole AIDS thing, the rest of the shows have all done the AIDS thing.

$\mathrm{K}$ : Young and the Restless has a huge AIDS thing.

JE: Ya they did it on Another World eons ago, and they still have not done that. And they don't even have anyone who is gay on the show at all they haven't dealt with that at all.

R: Maybe Mike could be.

JE: No, he had that woman in Israel, and he's got that kid and all of that $\mathrm{R}$ : ya what was her name. 
JE: she was a doctor, like Robin, was it Robin.

JO: ya

JO: I also read somewhere that her.

JE: I just can't stand Kristen. Kristen is such a tramp now. We totally talking about this today. What happened to Miss Pias, could never be with a Priest, went to church everyday, totally close to Father Francis.

R: ya

JO: Totally, like,

JE: Now she's like queen slut she runs around in these like, like what was that cheetah skin outfit she had on last week?

JO: ya

JE: You know what I'm talking about and the high heeled shoes, today she had these

high heeled shoes on and this shorts outfit. It was, she's just nasty now.

$\mathrm{K}$ : What does John say?

JE: And that whole ice cube scene they did, where they were like melting the ice.

$\mathrm{R}$ : Ya down in the basement.

JO: And John is like a hair ball.

JE: Oh I know, he is so not attractive.

$\mathrm{R}$ : The one thing I don't like about Marlena is that she is just so, yes.

JE: They are totally trying to polarize them they're making her like good one and Kristen the bad one, the temptress 
$\mathrm{R}$ : She is bad

JE: She is getting really bad, she's like getting really psycho

R: "You love Kristen, you love Kristen, Kristen's the one, I'm here," "I love you

Kristen but I love Doc more."

JA: What, when did that happen.

JE: oh yesterday.

JA: oh you're kidding.

$\mathrm{R}$ : But he was under the drug.

JE: Ya the drug.

JO: She says "who do you love" and he says "I love Doc, I could never love anyone but Doc."

JE: She freaks out she like takes Marlena's picture and goes "This is the only thing you have left." She goes like this with her totally long nails. Then she totally looks at herself in the mirror and says "you will never let John see this side of you or you will lose him for ever."

JO: Then that's when she sees what's her name in the back ground, the lady in white.

$\mathrm{K}$ : Now what happened?

JO: OK guys total trivia question.

JE: OK

JO: What are the effects of Validan? 
JE: Well if you mix it with alcohol you can still perform, but you'll never remember what happened.

JO: But you won't remember who screwed you in the morning.

$\mathrm{K}$ : What in the hell are you talking about.

JO: Validan is the drug.

JO, JE: That Sami gave Austin.

JE: And then she gave it to Kari, New Years Eve when she moved Kari and Lucus' body in the same room. They never had sex but they think they did, that is so lame. JO: I'm sure like Kari would know in the morning.

JE: I'm sure

JA: I know

JO: And besides that I just wish there was porno days. I mean can you imagine JE: Like when she came out and was giving Austin that back rub.

JO: Kim and I always say how hard we would laugh.

JE: She was like trying to be all in that bath robe. It was buggin'

JO: And love the way that Sami is like eighteen and she has like all these like negligees'

JE: I know, remember when she totally planned to be nude so he would walk in and see her nude. And they like showed the side of her body and her hair was like covering the front of her. She was like " Austin I didn't her you come in." He was only like calling her name through the sheet. 
JO: Like you can't hear through a sheet.

JA: She is so unattractive anyway.

$\mathrm{K}$ : Why don't you just cut her hair and give her a little lift or something you know?

JO: Cut that damn hair off, at least they cut Kari's hair off.

JE: But Kari's starting to dress really just nasty. She is doing that whole retro 70's thing. And Austin is not sexy. When they did that photo shoot. I was like

JO: Did you see where Austin, Austin wears Wranglers.

JE: I know, like with the big wide belt.

JO: He where's the ones that aren't washed, like Dad buys, that are so blue with the orange, like put sunglasses on. And he walks like, "I'm a Wrangler man."

JA: And he wears like that ten necklaces around his neck.

JE: And it's like when was the last time they worked. Have you noticed that. I hate how Bo totally does that, "where did you get the horse drawn carriage, tuxedo, and dom parinote champagne" "I know this guy down at the stable he owed me a favor." Like not.

JO: Do you remember the old Sean Douglas?

JA: He was bad.

JO: The old Bo is married to Jamie in real life, Kari and the old Austin are together in real life

JE: One of your friends down in California knows Lucus, he is such a bad actor 
JO: ya one of my friends, went to high school, and he is like a total drug taker, they didn't tell about Austin and Kari until it went off the air.

JE: Who is this?

JO: The old Austin and the real Kari.

JA: The old Austin's on Melrose.

JO: ya Patrick Muldune

JE: He's dying on tonight's show.

$\mathrm{R}: \mathrm{He}$ is, why?

JA: I know why.

JE: Because he raped what's her name.

JO: This girl in who lives in my apartment complex went to high school with Lucus and she um and Lucus went, he was from up north she says he is total partier that he like smokes pot all the time. And makes a joke out of it.

JE: They're already talking about plastic surgery for the woman in white. They're going to fix her up and make her look like Kristen. They're gonna dye her hair blonde totally.

$\mathrm{K}$ : Who is she?

JE: She was on Santa Barbara.

K: huh, Santa Barbara, when?

JE: Wait till you see today's, they show tons of her in retro feeds in Peter's mind. She was the actress on Days who played the Mother of the girl with black hair who had the 
post traumatic stress because she had been raped by her uncle who was the best friend of the cop brother who was best friends with Kurt.

R: Woaw

JA: What?

R: Santa Barbara

JE: Don't you remember that, she had the doll, "the dolly will tell you no," and she was a journalist and she had a total crush on.

R: Oh ya

$\mathrm{K}$ : Is Santa Barbara still on?

$\mathrm{R}$ : Penny, Penny is her real name.

JO: No, years ago. But um I think that what's gonna happen I think on Days right now, is that, Peter and Jen are on the actual plane.

JE: ya

JO: and Peter just said I need to go back to Salem.

JE: Right

JO: I think they're not going to be able to get back to Salem, they're gonna get some crazy like, because Kristen is gonna like screw up the woman in white.

JE: When are we gonna find out, when is it gonna come out that Peter totally drugged Laura, and the whole fact that he killed what's his name, Daniel. That has not come out yet.

$\mathrm{K}$ : And what about Jude? 
JE: ya and well everyone knows about that because Jennifer saw that whole thing happen.

JO: No she didn't see it happen, she doesn't think that he killed Jude.

JE: Well, she thinks, well she knows that he shot him.

JO: ya

JE: But she doesn't realize that it was on purpose.

JO: ya it's pretty weird.

J: OK so who are your favorite characters.

JO: On Days?, um Austin.

JA: oow no

JO: and Kari and Vivianne.

K: Mine's Austin and Kari I like um Bo.

R: I like Bo and Hope.

JA: I like Bo and Hope.

JO: It's kind of hard because we seem to like the characters pertaining to their storyline.

JE: yes

JO: Like I always change like sometimes I love like I kinda like Kate's storyline right now.

JA: I do too. 
JO: 'Cause she's just kind of crazy and like evil and like trying to get to the bottom of Sami, cause I hate Sami.

$\mathrm{R}$ : I think we can all agree on that one.

JO: But I love like I love Vivianne always because she's so crazy. But I like Kari and Austin because I want them together so bad.

JO: But a constant person would be like,

JE: Marlena

JA: I always liked Billie.

JA: Like Kari's a constant and,

JO: Is Billie, Billie was a total constant for you, you loved her.

JE: Oh I love Marlena, the only thing I like totally have to fight for are like when Austin and Sami together that bugs the crap out of me and I cannot watch Kristen and John, it's so funny.

K: I use to love Kristen and John together.

JO: You did, she loved Kristen and John.

JA: I like Jack, Jack is wow.

JO: ya Jack

JA: I love Jack, I love Peter's power like he would do anything to keep her.

JE: There is nothing attractive about him at all.

JO: You think he's good looking?

JA: Sometimes when the just cut his hair. 
$\mathrm{K}$ : Peter is not bad looking

JO: With is shirt off, wow.

R: I only like him sometimes.

JA: You guys, if he came to your house and said come on, you would be like,

JE: I would say get the hell out man, now Jack if Jack or Bo came to my house I would be like bring it on.

JA, JO, K: ya

R: oh if Bo was in my house, watch out bye Kevin, I am not kidding.

JE: Jack is only 5'8' - 5'9'.

JA: Well so what, we're all short.

JO: Jack is fine

JE: I think he is so cute though but you know what? I'm totally sick of his, do you watch Another World.

R: ya I use to all the time.

$\mathrm{K}$ : Young and the Restless is good now.

R: I use to watch Young and the Restless, take my little soap opera break, Another World, Santa Barbara and Days, for years.

JA: Yep, but I don't know what's going on.

JO: Young and the Restless, then Perry Mason, Another World, Santa Barbara and Days. From Eleven to Four we just sat in front of the TV. 
R: I watched Santa Barbara from the very first day it showed to the very last day it showed.

JE: I can totally remember Days of Our Lives when we were kids.

R: Back when Hope was a little chunky thing.

JE: When Greg and Julie were still on the show when Marie was on the show.

Remember when Marie shot Liz, because Liz was together with Doug, yes and she got shot in the throat and they got married in prison.

JO: I like that whole Steve, that whole Steve, that story.

R: I loved that.

JE: No but here's the thing about Steve though, Dave stole Steve's coffin, Steve is totally coming back on the show.

R: ya but when.

JO: Stole his coffin?

JE: Yes, right after it was Stephano, Stephano who stole Steve's coffin.

JO: oh who was the senator's son name who, with Kayla,

JE: Jack Devereau

JO: no

JE: Senator, Devereau, hello people.

$\mathrm{R}$ : oh ya it was.

JE: Kayla was suppose to get married to Jack and was dying with the deathly illness. R: Didn't he rape somebody. 
JE: He raped um,

R: He raped,

JE: He raped Kayla.

JA: No I'm talking about the guy that Hope almost married.

JO, JE, R: Oh

R: That's like going way back, I know what his name is, he has gray hair blue, eyes, kind of a good looking guy for an older man.

JA: He rescued her family

JE: No Haley was the private detective who carried her out, and to her wedding dress

down the isle, "pucker up baby."

JO: Hello, is Kayla coming back.

R: Kayla I don't think would come back.

JE: Just guest appearances, like when Tom died and stuff.

R: ya cause she's on General Hospital now, Kim came back, Kim,

JE: Yes, and Maggie and his daughter Melissa.

R: Remember Melissa and Pete?

JE: Yes.

JA: oh I loved them.

JO: Melissa's coming back on the show, I read in that same article.

$\mathrm{R}$ : What?

JO: They're working on her story. 
JA: Hey how about Melissa and Mike.

JE: 0000

R: Wait, they're related.

JO: ya they're related.

JO: Melissa's gonna be the one, Kristen's gonna be totally screwed they said basically and Melissa's gonna be the one who's gonna help work out Jen with Jack and Peter. Ya cause Kristen can't take sides.

R: Is it gonna be the same Melissa?

JO: I don't know who the actress is I'm just saying the character is.

R: I hope it is cause I like her.

JE: Lucus and is Mike and Jennifer's half brother. Check that out.

R: Since when?

JE: Since always, he's they're half brother, Lucus is Jen and Mike's half brother and they have totally not done any thing with that storyline, he's Bill Horton's son cause of Kate's affair and they have not even done anything with that storyline.

JO: oh well

$\mathrm{K}$ : Do Kate and Laura get along now.

JE: No

R: OK wait a second, if they bring a Kayla back it's not gonna be the same Kayla, it won't be, you don't like her, I liked her.

JE: You know why I don't like her she looks just like Brenda 
R: Who's Brenda?

JO: Who told you the same actress was coming back for Billie?

$\mathrm{R}$ : um a magazine.

JA: I read it, ya soap opera digest.

JO: She has gotten a lot of movies, I mean she's going big time.

JE: I don't understand this whole, OK one thing that pissed me off was how what's her face, Bo's girl before Billie, the doctor

JO: Karlee

JE: Karlee, and Lauren just disappear to France with Nicky and they never like, you don't know how they're doing, she has been buried alive basically and poisoned by an orchid and then just disappears to France and everybody is OK with that.

R: No

JE: It was so weird, they did not handle the closure of the story at all, it's like she came out of it and had no memory of anytime beyond Lauren and disappears to France, like Bo's really going to let her go in that situation.

R: well didn't that just really just fall apart anyways and she started having memories of her and Lauren.

JE: No she got drugged and she lost all of her memory. She lost like ten years of her memory and the last thing she remembers is when she was with Lauren.

JO: I thought it was pretty lame, I mean it was totally lame how they were just like, oh OK, um they just totally, like Bo who when ever he has Hope back in his life 
JE: you're the only one I've ever loved.

JO: you're the only one I've ever loved and it's like oh OK but what about Karlee and Billie and he just always forgets them.

JE: And Sean like always wants them to be his mother.

JO: Well come on the poor guy, the guy hasn't had a mom.

JE: And where in the hell does he sleep cause I'm sorry but there's only one bedroom on the boat, there is only one bedroom on that boat.

JA: He sleeps with the Hortons

JE: Half the time, he has no dad basically.

JO: I love the way they other day Bo's like well he needs a mom, and I'm like well how about a dad.

JE: How 'bout if you go to work for a day.

$\mathrm{K}:$ He doesn't even work

JE: I know, what happened to the Horton Center, I mean we have not seen the Horton Center, and Shenanigans?

JO: It's the Brady club

JE: No Shenanigans had the loft.

JE: We were trying to trace all of John's women, and we could never think of her name do you guys remember what it was she had red hair she had total buggin' blah face,

JO: You remember her, right? 
JE: And she was really close to Kari and it was right when Kari was getting training bras. Cause they did all thing with her training bras.

R: Oh Jillian, no not Jillian.

JA: I remember her but I can't.

$\mathrm{K}$ : Kari's been in there for years.

JE: On and off though, well she went to Europe and lived with Anna for a while.

R: I liked her when she was like.

JE: Don't you remember her name, cause he went like Marlena, then to this red head, then to Diana, then to

$\mathrm{R}:$ Who is Diana?

JE: Anna then Marlena,

$\mathrm{R}:$ Who is Diana?

JE: Diana's dad ended up being the third player in the pawn game, it was DiMira, Dono and that Third guy, Diana's dad, I can never remember her name, she has a mole on her hand, she plays Laura on Young and the Restless, General Hospital or what ever.

$\mathrm{R}:$ OK that's what I thought.

JE: Her, she was on there forever and left one night in the middle of the night and left them a note, saying "we can never be together." The last scene of her was the mole on her hand leaving the screen, remember her with the mole.

JO: Who? 
JE: Diana.

K: I remember Anna.

JE: She was awesome, Anna and Tony, do you remember Tony's evil twin

R: I was just going to say, what was his name?

JE: Who murdered Renee, "I have to survive."

R: What was his name.

JO: Tony has a twin?

R: He's dead though.

$\mathrm{JE}$ : This is another thing that really pisses me off though you guys, Tony is not

Stephano's son, Tony is Stephano's nephew, he has always been Stephano's nephew forever. And now they try to play the whole thing off and now they try to play the whole thing off like "don't you ever compare me to my father again." But it's not even his dad.

R: I thought they like I thought the made an issue of that like one reference, in the past couple of years.

JE: Well, they were talking about the blood line and DiMira's needing a son and all this kind of stuff.

$\mathrm{K}$ : Well everyone in Salem is a DiMira

JE: In some way or another.

$\mathrm{R}$ : Now is Tony dead?

JE: Everyone in Salem is some how controlled by Stephano. 
JA: Tony is up with the doctor who's on the review committee of Jonah's medical board statement, and all the sudden that weird guy they brought out of no where with the cell phone and they were going to dig up dirt on doctors in the hospital.

JE: It was so stupid.

R: Now is Tony dead for good.

JE: ya

R: Is Stephano ever gonna die for good.

JO, JE: No.

K: Just because Marlena shot him at point blank from two feet away.

JE: He's come back to life like what, twenty times.

$\mathrm{K}$ : Well what's so big about Aramid, they don't know yet?

JE: They haven't revealed it yet, but they know Mays on Blanche, that's all John's remembered, under the drug

$\mathrm{K}$ : Is what?

JE: Mays on Blanche, New Orleans, um they um

$\mathrm{K}$ : what's so big about John's past, I thought we cleared that up.

R: I don't think we'll ever clear it up.

JE: He killed (unintelligible) dad, he was an Alamain, and then they thought he drown and then he went to France, and he was a Cluso inspector who was chasing this jewel thief, and then he was a priest in New Orleans, he got kid napped by Stephano, his mind was taken away and he was turned into a mercenary killer at some time like a 
super trained solider, then brainwashed into thinking he was Roman and then back to Salem to be Roman, his real true, true genetic identity is he's an Alamain. He's Laura Alamain's brother, but he's been like five different characters because, Stephano.

R: Wasn't he suppose to be like and older brother?

$\mathrm{K}$ : Wasn't he the one that killed, does the lady in white know that ?

JO: No they just connected when she was being held captive or something like that.

JE: But they know each other from Aramid before and that's what he hasn't

remembered yet. Because he met her in New Orleans, he remembers but he thinks they knew each other when they were in Aramid.

JO: They thing I love, you guys, the best is like those scene's between Austin and Sami when he's like "Sami you've been through a lot, you know you had to grow up really quick and you had my baby." And it's like "oh thanks Austin." It's like not to mention like when your sister got kidnapped, then your mom got kidnapped for a couple of years, then you kidnapped your little sister and then you had your dad for a while and then you found out that wasn't you real dad.

JE: I know.

JO: And then your real dad got kidnapped and then your supposed other dad came back.

JE: Had and affair with your mom. 
JO: And all this happens in like five years, I'm just saying that all he gives her credit for is that you have grown up really quick all you've had this baby for me, like not to mention all this other stuff.

JE: My favorite episode they ever had, remember that evil guy that was like always totally after Anna and the Anna and Tony scenes, I can't think of his name right now, does anybody remember him, he had the really kinda leathery face.

JO: Who?

JE: I want to say his name is Charles or something and he was always around Anna, and he was trying, one show they totally advertised the show where they had no script. They were gonna let the cast go crazy. And the cast could do what ever they want for the whole episode and then the writers would write their way out of it and they did this big promotional thing. Nobody saw that? You have to remember that because that's when Tony and Anna got married and then and they took off to the Far East for their honeymoon and she was kidnapped into the harem, remember that?

R: ya I remember that.

JE: And they were married but they weren't really married because the guy he had brought in to marry them was not really a priest. They totally they let the cast go crazy that day and then the writers had to write their way out and the cast could do what ever they wanted that day, it was like a total unpredictable episode. And that's when they came up with the whole Jo being in love with Neil Curtis thing and R: oh ya 
JE: Jack's mom, remember that, Jo?

$\mathrm{K}$ : Who's Jo?

JE: Jo is Jack's mom, who's sister is married to Victor's nephew.

R: What? Victor's nephew.

JE: Ya what were their names, buggin' girl who's Paulina on Days of Our Lives now.

Buggin' fat blonde chick with the short hair.

$\mathrm{R}$ : What was her name on Days.

$\mathrm{K}:$ Who?

JE: Victor's nephew and the buggin' blonde.

JA: Adrian.

R: Adrian and Billy, who's on.

JA: Justin

$\mathrm{R}$ : Billy is his real name.

JE: Ya Justin is Victor's nephew, they live in Texas now on the show and,

K: Oh Jo, Patch's mom.

JE, JA: yes

$\mathrm{K}$ : Who use to be the house keeper?

JA: Ya Jo died.

JE: Ya the real Jo died remember when Jack,

R: In real life. 
JA: Remember when Jack said I hate to say that Jo or what ever her names is passed away?

JE: Did they kill the character?

JO: The character in real life died.

JE: Right, but the character on the show.

JO: No that had another person come in and play her.

JE: But right now on the show Adrian and Justin are in Dallas and Jo is in Salem.

R: Then how come we never, that's weird.

JE: Jack and Patch, we found out that Jack and Patch are really brother and sister.

$\mathrm{K}$ : Jo's not still in Salem.

JE: Yes she is, she sometimes watches Abby, they say things like "where's Abby," "She's over at Jo's." "She's at your mom's house"

JA: They do?

$\mathrm{K}$ : You totally get into this.

R: No this is JE, "I have to go watch three or four Days of Days"

JA: Are you sure?

JE: Jo is in Salem now on the show, she is I'm telling you she is.

JA: I never heard that.

$\mathrm{K}: \mathrm{OK}$

JA: Have you, have you.

JO: Don't ask. 
JA: JE you're out there.

J: So why Days of Our Live over other soap operas?

JO: God I don't know, I love like.

JE: I loved Santa Barbara more than I liked Days of Our Lives but they took it off the air.

JA: I just started watching it because of mom.

$\mathrm{J}$ : What did you like about it better?

JE: Santa Barbara? Well because it was a totally at that time the writing was totally more realistic storyline than what they were doing with Days. But I really lost interest in Santa Barbara towards the end because they started doing this strange Eden magical thing, where they were like disappearing into magical caves, and fires would light by themselves, then they turned themselves into Santa Claus. I mean it got towards the end of the show it just got unbelievably stupid.

$\mathrm{K}$ : That's no longer, is it?

R: No

JO: Um I think I like Days the best, maybe for you or you too, but it's just because I've watched it for so long. And I've tried to get into other soaps but I only watch, like I like a lot of night time shows. So, I'd rather, if I'm gonna watch a daytime show that's it. I mean it's too hard to start now.

$\mathrm{R}$ : Ya because you can like, I mean since we've watched it for so long you can go for like a year without watching it. 
JE: And Mom has watched Days of Our Lives since it started. Mom has watched it since we were kids.

JA: That's how we got into it.

$\mathrm{K}$ : So did my mom.

R: You could like totally like miss it for ages and still know what's going on.

JA: I think I like it for the same reason, I have just watched it for so long.

$\mathrm{K}$ : We watched it for years, that's what you grew up watching.

JA: I know all the back ground, but I do, it's not that I really like it all that much but I feel like I have to keep up on it now.

$\mathrm{K}$ : So if you do miss it,

JE: Oh do you do that threaten to quit watching it thing.

JO, JA, R, K: Ya

$\mathrm{R}$ : It works for a while for me but I get back into it once in a while.

JO: I just like it because it's like total escape and it's just so funny, cause it's and I think a lot of it, it's Days cause I feel it's like a total connection with the most of any other soap that I've noticed. Like with any person. If they're gonna watch any soap opera is like nine times out of ten it's Days of Our Lives.

JE: Or General Hospital.

JO: Don't you think, I think it's Days mostly.

$\mathrm{K}$ : Or Young and the Restless. 
JE: All my sisters watch it, in fact when our sister went to Europe our other sister taped the entire show for a year, so she could watch it, so she would not miss a single episode, cause they're like five years behind us in Europe on their episodes so.

$\mathrm{K}:$ They are?

JE: Oh ya, when I was in France, Santa Barbara was still on the air. The original, I can't think of his name right now, oh the original C.C. was still on, and there were three C.C.'s before that show went out. C.C. Cadwell.

$R:$ They went through three Kelly's too.

JE: Ya they did, so we all talk about it when we get together and we watch it when were all home together. So it's like I want to keep up with it just because it's like a joke, it's like something to talk about with my sisters.

JA: Ya that's true that probably has something to do with it too, it's like JO: Making jokes or

JA: Then there' a couple people at work that watch it so, you know.

R: If I ever miss and episode I know I can call JE and she'll keep me up to date.

JE: Ya and the big joke in our family is "oh may God there was a tragic explosion and Shane lost his memory again. That's like the big joke in our family, cause they always do that, they always have people lose their memory it's so stupid.

R: Kim lost her memory didn't she, no.

JO: Do you want to talk about with adolescent's or anything. 
$\mathrm{J}$ : Not too much, you guys watched it in high school, do you think your perspective is different now.

JO, JE, K: Ya

$\mathrm{K}$ : Definitely, I think when you're in high school you kind of like actually experience

it.

R; JE, JA: Ya (all laugh)

$\mathrm{K}$ : Now you just laugh at it like, you know like oh my god.

JO: and you totally think that that's like what a relationship is suppose to be like

R: $\mathrm{mm}$ hmm.

$\mathrm{K}$ : Ya exactly.

JA: Like those are real conversations people have.

JO: But I think it is highly, highly, highly influential.

JA, K: Oh ya

JO: I think that a lot of the vindictiveness like you know the way that people get back at each other and like the revenge and the lying.

JA: I will do anything to get that man.

JO: I mean I really think that impacted, not like I ever did that, or what ever but I mean I think that people really like look to that and think of it as like a lesson or you know an idea or something that just really.

JA: Well and you have to admit like when something happens on the show that's really romantic like between a couple like if a guy does something. 
JO: You're totally, Oh I wish oh I wish my man would do that for me.

JA: So everything else pales in comparison.

JE: Like Steve and Kayla's wedding, Steve signed the Rose on the Yacht.

K: Steve and Kayla's wedding.

JE: Steve and Kayla's wedding and she couldn't talk and he signed the Rose.

$\mathrm{R}:$ Oh that's right.

JE: and we were bawling, we were totally bawling.

JA: And we were like Oh I wish my husband would do that.

JO: But even like on a smaller scale, it's like you know they always have candles lit, or "let's order dinner in honey." And then it's like you know your boyfriend or your husband comes home and they're like "hey I'm ready for dinner." I mean there's just like a small part of you that's really disappointed.

JE: They're always look like perfect. Marlena's only been in that dungeon, held captive.

R: And she was gorgeous, had make-up on, has the silk suit on you know.

JO: I think too that it kind of distorts your image of like, kind of like a normal perception of reality, like I know for me, like this is a totally true example. Like I had to get out of work last week cause I had an interview. And instead of just saying I had and interview, I said a friend of the family had a stroke. (Everyone laughs) JE: And his name was what? 
JO: So she asks me out of the blue what is his name and I could not think of anything else and before I could even stop myself I said, "Oh Victor." And for me it's like what if I go back on Monday and she says nice try Victor didn't die. I was like and for me I was like "what am I doing?" I just totally coulda just said I have an interview for a real job, this is a temporary agency that I work for. I mean it would be no problem for me to say I had a damn interview but no instead, I choke. I said I have to go take care of the kids, I have to be there because this man had a stroke.

K: Victor had a stroke.

JO: Victor, I mean and that to me is really scary. I mean why would I normally say that. I mean not that that happens to anybody but that does cross your mind. I have to have a lie, people call me all the time for excuses.

JE: I can't come today because my sister's, brother's friend who is married to another friend of mine had a baby that got kidnapped so I totally can't come today. JO: Well, I don't do that.

JE: No

JO: I think it really does kinda you know like gives you a different perspective. JE: I think you have major tragedies you tend to melodramatisize them more, you get more dramatic about it.

JA: No, like somebody will be telling a story about something and I go oh that happened to, oh ya then is totally hits you. 
JO: It's totally from Days and oh yes that happened to my friend. You know. It's from Days of our lives and you get mixed up for a minute. It's hard to cross over. JA: No wait it's a TV show.

$\mathrm{K}$ : Oh it's like something that happened in my life.

JO: Ya or like you think you identify, like you think you totally know that person. Oh Sami, like she called last night.

JA: Well, I don't know about that.

JO: Well ya I mean I'm like kind of exaggerating but it's weird.

$\mathrm{J}$ : So if someone were to come in on our conversation they would of though we were talking about JO: Our best friend.

R: Like OK at Mom's that day when you and I were just going "and she wears that napkin over her and oh John."

JE: Grandma got totally upset because she did not know who we were talking about. R: Well no it was Terry, Terry looks at Krista and goes are they talking about a family member.

JE: And we were like no.

R: And Krista's like they're talking about, cause she knows what, cause she doesn't miss an episode.

JO: Ya that's very true.

R: Oh it was funny though. 
JO: You know, like you know them, like they're your best friend or something.

R: Grandma did feel that way, she was like who are you talking about.

JE: And it's like you live to like guess what they're gonna do. We like totally know what's gonna happen on the show. We knew six months ago that the woman in white was Kristen and Peter's mom. So why do we keep watching, like we had to get. When I saw the clip that was like "Tomorrow the woman's identity is finally revealed." I was like I cannot miss that. Like I didn't know what was gonna happen. You know I knew what was gonna happen. But I had to see it for myself.

M: When I was, I had all these kids when I was watching two at least sometimes three a day. It was, I think, I look back on it and I think things were always worse in their lives than they were in mine. Which gave me a feeling of at least I'm not as bad off as so and so you know.

R: That's true.

M: But there came a point for me when I knew, it's like JO's saying oh my good I've lied. When Jessie on General Hospital. She was pregnant and about to have the baby the baby two weeks ten days to come, of labor. They went through everybody else in the soap opera's day while she was in labor, about every you know twice in the show they would slip over to the labor and she would be there going.... And I would say to myself my god what is going on here, my god she's never gonna to have that baby. You know I mean it was terrible. In the second week I said, when Jessie has that baby, I'm gonna see her through until she does, I'm gonna stay with her, when she has that 
baby I'm gonna quit cold turkey. And by god I did. I never have watched another one consistently.

JE: I can remember when we were kids in the old family room, in the brown house, JO and I would sit there with you and watch Another World and Days of Our Lives. That's how we knew about Liz and Neil and the whole original Stephano crew. JO: Anything else you need to know specific.

J: No, when you watch where are you.

JO: Sometimes friends or family but basically pretty much alone. Or with my roommate.

JA: Wednesday or Thursday I watch three or four days worth and I ff through. Most everything except the good scenes.

JE: I watch it at night and I start watching it alone and my husband swears he hates it but he always ends up sitting next to me and watching the entire thing, always. He never misses and episode. And he'll tell you that he hates it and he'll tell you he doesn't know what's going on.

R: My husband watches it.

JA: Ya I watch it alone though, basically unless one of you guys happen to miss an episode. My husband bitches in the background, "why do you watch that stuff, turn that off."

J: Do you find yourself talking to the TV?

JO: Ya 
JA: I'll be like come on just say it. You know I'll be like with Jamie the other day the other day with Kate I was like just say it Jamie.

JO: Big time.

JE: It just keeps draggin on, I'm getting tired of it.

JA: I just loved it when they confronted her in Victors office. That was like the best thing, I hung on every word.

$\mathrm{K}$ : What happened?

JE: Kate totally confronted her.

JO: It was Kate and Victor had Vivianne and it was Sami, Lucus and Austin.

JA: And Jamie was there too.

JO: And Sami lied her way out of it she got out of it, believe it or not.

JE: She did the big crying sob story.

JA: Ya and she ran down the stairs and Austin or somebody came down and blah blah blah.

JE: Oh no Vivianne.

$\mathrm{R}$ : That happened at the same time.

JE: This was before Victor had the stroke.

J: Do you find any of this stuff useful or do you learn anything?

JO: Um some of it, ya I think some of it.

JE: I definitely learned the virtues of using Validan. 
JA: The only thing that I can think of about that would be like it does give you a perspective or it gives you a reference point for, well relationships. Like I know we were joking about raging on about the guys. But it gives you this something, not that it's the best, probably not the best model. But, at least its something.

$\mathrm{K}$ : It can give you idea.

JO: I think the good thing about you know usefulness is also that normally on the show there's like the epitome of good and evil. You know normally like against each other. And I think from like a good perspective you know if you really identify with a character you could like if you really identify with like Marlena or something who is truely like a saint you know or whatever I mean it would be a good role model. I mean if you truely were like Marlena, I mean you know you would be a really good person. For the most they dress nice and they all look good. You know some of them. JA: Ya great clothing ideas.

JO: You know for the terms of usefulness oh sure I love their hair styles I love their clothing styles. I love I mean a lot of ways they act and stuff and some of their advice, like how realistically they handle, like if you've done something wrong you just go and tell the person. Even though it doesn't come out for two weeks for those two weeks they have been trying.

JE: Like when ever they tell right away I am so proud of 'em.

R: Do they ever do that though?

JE: Ya they have a couple times they've had stuff come out right away. 
JO: And they've have actually, I mean they've dealt with some really good things. I mean they don't really deal with sex things, but Sami went through a really big eating disorder, you know dilemma. And the have dealt some core issues like teen sex.

$\mathrm{K}$ : Didn't they have an alcoholic on there.

JE: Ya it was Jo.

JO: You know I think they deal with some of those.

JA: Some issues.

JO: Some issues.

J: Do you feel like you can relate to any of them?

$\mathrm{K}$ : Ya like things we have in common or something.

JA: Some, I'm sure there is.

JO: Or situations, currently it's not but it has over the years.

JA: On again off again a certain situation happens and you like that way hits home. JO: Like right now probably Hope and Bo like Bo wants her to be a mom and Hope wants to have a career. I'm sure that's really probably hitting a lot of women right now like totally identifying with Hope or what ever. I mean I really would think that that a lot of situations are like that. And probably a lot of people you know that really love somebody that can't get 'em you know.

JE: The only couple on that show that I think are even decent role models are the super couples that have been together forever. Like Tom and Alice, when they have been married for years. 
JO: Well they don't have to be role models, just anyway you can identify.

JE: Like Caroline and Sean.

$\mathrm{R}$ : Ya but that's not even a good role model because she had an affair.

JE: Right, but they like worked through it, and stayed together.

R: Ya they did overcome their

JE: But I've noticed that Days has gotten really religious the last year. I mean there's

like a big focus on God. They did a lot of prayer stuff, lot of church stuff, they did that whole demon thing.

$R$ : That bugged in a way.

JE: Ya but even they kind of kept it up, I mean with Kate going into the church to pray for Victor to be alive and Vivianne going into the church.

JA: They've always done that though the chapel at the hospital

JE: Way more than usual though, way increase.

R: That little chapel there.

JE: Way increase on that lately.

JO: Ya I guess so.

JE: And they're rebuilding the church and all the you know.

$\mathrm{R}$ : I missed that one.

JE: And but Father Francis has totally dropped the face of the planet. He's in a coma somewhere in the hospital.

JO: He left the Priesthood. 
JE: John left the Priesthood.

K: Well John applied to get out of the Priesthood but we never know what happened.

R: Oh he did, it said something about it.

JE: And now Kristen

R: Oh my God she was bugging me because she was like, oh I don't like her I don't like her at all.

K: Would you say she's a great actress.

$\mathrm{JE}:$ No, there are not really any good actresses

R: A girlfriend says she must have been a man before, well she's built like one, but she use to be Ashley on the Young and the Restless.

JE: I was pretty bugged by that whole Jude thing, they really dragged that out.

$\mathrm{R}$ : isn't that is that still going on yet, how did that all end?

JE: Peter shot him.

R: Well that's pretty final.

JO: Anything else.

J: No that's all, thank you. 